\title{
PEGylated silk nanoparticles for anticancer drug delivery
}

Thidarat Wongpinyochit ${ }^{1}$, Petra Uhlmann ${ }^{2}$, Andrew J. Urquhart ${ }^{3}$, F. Philipp Seib ${ }^{1,2 *}$

(1) Strathclyde Institute of Pharmacy and Biomedical Sciences, University of Strathclyde, 161 Cathedral Street, Glasgow, G4 0RE, UK

(2) Leibniz-Institut für Polymerforschung Dresden e.V., Hohe Strasse 6, 01069 Dresden, Germany

(3) Center for Nanomedicine and Theranostics, DTU Nanotech, Technical University of Denmark, DK-2800 Kgs. Lyngby, Denmark

KEYWORDS: silk, Bombyx mori, silk nanoparticles, PEGylation, drug delivery, breast cancer 


\section{ABSTRACT}

Silk has a robust clinical track record and is emerging as a promising biopolymer for drug delivery, including its use as a nanomedicine. However, silk-based nanomedicines still require further refinements for full exploitation of their potential; the application of "stealth" design principals is especially necessary to support their evolution. The aim of this study was to develop and examine the potential of PEGylated silk nanoparticles as an anticancer drug delivery system. We first generated $B$. mori derived silk nanoparticles by driving $\beta$-sheet assembly (size $104 \pm 1.7$ $\mathrm{nm}$, zeta potential $-56 \pm 5.6 \mathrm{mV}$ ) using nanoprecipitation. We then surface grafted polyethylene glycol (PEG) to the fabricated silk nanoparticles and verified the aqueous stability and morphology of the resulting PEGylated silk nanoparticles. We assessed the drug loading and release behaviour of these nanoparticles using clinically established and emerging anticancer drugs. Overall, PEGylated silk nanoparticles showed high encapsulation efficiency (>93\%) and a pH-dependent release over 14 days. Finally, we demonstrated significant cytotoxicity of drug loaded silk nanoparticles applied as single- and combination nanomedicines to human breast cancer cells. In conclusion, these results, taken together with prior silk nanoparticle data, support a viable future for silk-based nanomedicines. 


\section{INTRODUCTION}

The term "nanomedicine" was coined in the early 2000s and is essentially an umbrella descriptor for specifically engineered, nanosized therapeutics and imaging agents composed of multiple components ${ }^{1}$. Over the past three decades, more than 40 nanomedicines have entered routine clinical use ${ }^{1,2}$. The majority of these nanomedicines serve as imaging agents ${ }^{1,2}$, but interest continues in nanomedicines for drug delivery applications ${ }^{3}$. For example, more than a dozen nanoparticles are currently in clinical trials for a broad spectrum of indications ${ }^{4,5}$, including targeting of solid tumours ${ }^{6}$. Nanoparticles are particularly well suited for tumour targeting because they can exploit the leaky neo-vasculatures and poor lymphatic drainage of solid tumours, thereby enabling their passive accumulation ${ }^{7,8}$. This phenomenon is widely described as the enhanced permeation and retention effect (EPR) ${ }^{9}$; this effect can increase the retention time of nanoparticles in tumours ${ }^{10}$.

The payloads of nanomedicines differ widely but they must reach the tumour microenvironment and often must deliver their payload to a specific intracellular compartment to elicit the desired pharmacological effect ${ }^{11}$. For example, anticancer nanomedicines designed for intracellular activation must complete their journey from the extracellular space to the desired intracellular destination via endocytic pathways ${ }^{12,}{ }^{13}$. Following endocytic uptake of a nanomedicine, the default destination is the lysosome, where the nanomaterial is exposed to low $\mathrm{pH}$ (typically 4.5) and lysosomal enzymes ${ }^{14}$. The use of stimulus-responsive polymers (e.g. pHtriggered) in the design of the macromolecular drug carrier can therefore promote drug release (i.e. lysosomotropic drug delivery) ${ }^{15}$. 
The vast majority of anticancer nanomedicines are designed for parenteral administration, which means that the nanomedicine must come into direct contact with the blood. This can trigger nanomedicine opsonisation; a process that is one of the most significant biological barriers for controlled drug delivery ${ }^{16}$. Specifically, unmodified nanomedicines are "tagged" by opsonins, subsequently recognized by the mononuclear phagocytic system (MPS) and eventually removed ${ }^{16}$. Therefore, surface modification of macromolecular drug carriers is a wellestablished strategy to minimise this effect ${ }^{17,18}$. Surface modification of particles provides many benefits: increased biocompatibility, decreased immune response, improved stability and delayed clearance by the MPS ${ }^{18,19}$. Therefore, PEGylated nanoparticles have a greater chance of reaching the tumour microenvironment when compared to uncoated nanoparticles ${ }^{18,20}$.

Biopolymers ranging from biological active polymers (e.g. heparin) to macromolecular drug carriers (e.g. dextrin, dextran, alginates, chitosan) and multifunctional materials ${ }^{21,22}$ are being used for a broad spectrum of medical applications. One natural biopolymer, silk, has been used for many centuries for suturing, and is licensed by the Food and Drug Administration (FDA) for use in humans for load bearing applications. Nevertheless, silk has only recently emerged as promising biopolymer for drug delivery ${ }^{23}$.

Silk has a robust clinical track record and excellent mechanical properties ${ }^{23,24}$. In addition, silk is biodegradable, and can be processed under mild aqueous conditions to generate various material formats ${ }^{25}$. A number of studies have detailed the manufacture of Bombyx mori silk nanoparticles using polyvinyl alcohol blends (particle size range $300 \mathrm{~nm}$ to $10 \mu \mathrm{m}$ ) ${ }^{26}$, 
emulsification ( $>6,000 \mathrm{~nm}){ }^{27}$, capillary microdot printing $(25$ to $140 \mathrm{~nm}){ }^{28}$, salting out (486 to $1,200 \mathrm{~nm}){ }^{29}$, supercritical $\mathrm{CO}_{2}(50-100 \mathrm{~nm}){ }^{30,31}$ or organic solvent precipitation (35 to $170 \mathrm{~nm}$ )

${ }^{32-34}$ (reviewed in ${ }^{35}$ ). Some of these studies examined the ability of silk nanoparticles to entrap and release (model) drugs ${ }^{26,29,32}$. Nanoparticles prepared from spider silks ${ }^{36,37}$ and chimeric silks (e.g. silk-elastinlike protein polymers) ${ }^{38}$ are typically formed using a self-assembly process; these engineered silk nanoparticles have been used for a range of drug delivery applications including small molecular weight (model) drugs ${ }^{39}$ and biologics (e.g. peptides, proteins and therapeutic plasmids) (reviewed in ${ }^{40,41}$ ). For example, bioengineered spider silk nanoparticles functionalized with a HER2 binding peptide and loaded with doxorubicin showed preferential uptake via receptor-mediated endocytosis in HER2 ${ }^{+}$breast cancer cells resulting in improved intracellular drug delivery when compared to non-targeted nanoparticles ${ }^{42}$. However, none of the described silk nanoparticles has been specifically refined to avoid the MPS. The optimum use of nanoparticles in vivo, however, typically requires "stealth" design principals. Therefore, the aim of this study was to manufacture PEGylated silk nanoparticles and characterise their drug loading and drug release characteristics, coupled with preliminary in vitro studies.

\section{Material and Methods}

\section{Preparation of silk nanoparticles}

Bombyx mori silk was extracted from cocoons as described previously ${ }^{43}$. Briefly, cocoons were cut into $5 \times 5 \mathrm{~mm}$ pieces, boiled in $0.02 \mathrm{M} \mathrm{Na}_{2} \mathrm{CO}_{3}$ for $60 \mathrm{~min}$, and then fibres were rinsed in $\mathrm{ddH}_{2} \mathrm{O}$ and air dried. The fibres were then dissolved in $9.3 \mathrm{M} \mathrm{LiBr}$ solution at $60{ }^{\circ} \mathrm{C}$, yielding a $5 \mathrm{wt} \%$ solution. This solution was dialysed (molecular weight cut-off 3,500) against $\mathrm{ddH}_{2} \mathrm{O}$ for $72 \mathrm{~h}$ to remove the $\mathrm{LiBr}$ salt. The resulting aqueous silk solution was cleared by centrifugation. 
Silk nanoparticle preparation has been reported elsewhere ${ }^{33}$. Briefly, the silk (5 wt $\%$ ) solution was added dropwise $(20 \mu \mathrm{l} / \mathrm{drop})$ to acetone, maintaining $>75 \% \mathrm{v} / \mathrm{v}$ acetone volume. Precipitated silk was then centrifuged at $48,400 \times \mathrm{g}$ for $2 \mathrm{~h}$, the supernatant was aspirated and the pellet was re-suspended in $\mathrm{ddH}_{2} \mathrm{O}$, vortexed, and subsequently sonicated twice for $30 \mathrm{~s}$ at $30 \%$ amplitude with a Sonoplus HD 2070 sonicator (Ultrasonic homogenizer, Bandelin, Berlin, Germany). The centrifugation, washing and re-suspension steps for the silk nanoparticle preparation were repeated at least twice more. The particles were analysed as detailed below and stored at $4{ }^{\circ} \mathrm{C}$ until use.

\section{Preparation of PEGylated silk nanoparticles}

For PEGylation, an aqueous $50 \mathrm{mg} / \mathrm{ml}$ silk nanoparticle stock was prepared. Next, $50 \mathrm{mg}$ of silk nanoparticles and $50 \mathrm{mg}$ of methoxypolyethylene glycol activated with cyanuric chloride (TST-activated mPEG, 5,000 g/mol, Sigma-Aldrich, St. Louis, MO, USA) were allowed to react in $2 \mathrm{ml}$ of $50 \mathrm{mM} \mathrm{Na} \mathrm{B}_{4} \mathrm{O}_{7} \mathrm{pH} 9.4$ overnight under constant stirring at $4^{\circ} \mathrm{C}$. After the reaction, the sample was centrifuged for 30 minutes at 194,000 $\times \mathrm{g}$. The absorbance of the collected supernatant was measured at $240 \mathrm{~nm}^{44}$. A calibration curve of activated PEG in $50 \mathrm{mM} \mathrm{Na} \mathrm{B}_{4} \mathrm{O}_{7}$ was used to determine the amount of PEG conjugated to silk nanoparticles.

\section{Silk nanoparticle size and zeta potential analysis}

Particle size and zeta potential of native and PEGylated silk nanoparticles were determined by dynamic light scattering (DLS, Zetasizer Nano-ZS Malvern Instrument, Worcestershire, UK) in $\mathrm{ddH}_{2} \mathrm{O}$ unless otherwise stated. Refractive indices of 1.33 for $\mathrm{ddH}_{2} \mathrm{O}$ and 1.60 for protein were 
taken for computation of particle size. The native and PEGylated silk nanoparticles were stored at $25{ }^{\circ} \mathrm{C}$ and zeta potential and size were determined at day 0 and 28 . The impact of $\mathrm{pH}$ on the zeta potential of native and PEGylated silk nanoparticles was determined by suspending them in $0.01 \mathrm{M}$ phosphate buffer saline (PBS) at $\mathrm{pH} 4.5$ to 8.5 and measuring the resulting zeta potential. For stability and aggregation studies SNPs and PEG-SNPs particles were added to $0.1 \mathrm{M}$ phosphate buffer and DLS measurements were performed.

Scanning electron microscopy (SEM) was used to visualise particles. Native and PEGylated silk nanoparticles were diluted with distilled water to a concentration of $1 \mathrm{mg} / \mathrm{ml}$. The samples were then pipetted onto a silicon wafer and lyophilized overnight. The specimens were sputtercoated with $20 \mathrm{~nm}$ of gold using ACE200 Low Vacuum Sputter Coater (Leica Microsystems, Wetzlar, Germany) and analysed with a FE-SEM SU6600 (Hitachi High Technologies, Krefeld, Germany) at $5 \mathrm{kV}$ and a 40,000-fold magnification.

\section{Fourier Transform Infrared Spectroscopy (FTIR)}

Fourier transform infrared spectroscopy (FTIR) was carried out using a PerkinElmer Spectrum 100 instrument over the wavenumber range of 550 to $4000 \mathrm{~cm}^{-1}$. All spectra were normalized and corrected for water signals. OriginPro 9.0 software was used to peak fit the amide I region of all spectra. Peak full width at half maximum (FWHM) was maintained at a fixed value to avoid over-fitting the data ${ }^{45}$. Untreated silk film, autoclaved silk film, freeze dried native and PEGylated silk nanoparticles were used to determine the secondary structure of silk and assigned as detailed elsewhere ${ }^{46}$. Briefly, the amide I region $\left(1595-1705 \mathrm{~cm}^{-1}\right)$ was identified and deconvoluted: $1605-1615 \mathrm{~cm}^{-1}$ as side chain, $1616-1637 \mathrm{~cm}^{-1}$ and $1697-1703 \mathrm{~cm}^{-1}$ as $\beta$-sheet 
structure, $1638-1655 \mathrm{~cm}^{-1}$ as random coil structure, $1656-1662 \mathrm{~cm}^{-1}$ as $\alpha$-helical bands and 1663-1696 $\mathrm{cm}^{-1}$ as $\beta$-turns. Silk films with a low and high crystallinity were generated as detailed previously ${ }^{47}$ and used as a reference for silk nanoparticles.

\section{Drug loading of silk nanoparticles}

The drug loading strategy used for doxorubicin (LC Laboratories, Boston, MA, USA) and propranolol (Sigma-Aldrich, St. Louis, MO, USA) was identical for native and PEGylated silk nanoparticles. Briefly, a $200 \mu \mathrm{l}$ nanoparticle suspension containing $10 \mathrm{mg}$ of silk nanoparticles was mixed with $200 \mathrm{nmol}$ drug in $1 \mathrm{ml}$ of $\mathrm{ddH}_{2} \mathrm{O}$. After a $24 \mathrm{~h}$ incubation period at room temperature, the sample was centrifuged for $30 \mathrm{~min}$ at $194,000 \times \mathrm{g}$. The supernatant was collected and the pellet was washed three times with $\mathrm{ddH}_{2} \mathrm{O}$. The combined supernatant was analysed for free drug in order to determine the encapsulation efficiency (\%) and weight percentage $(\% \mathrm{w} / \mathrm{w})$ loading. With the aid of propranolol and doxorubicin calibration curves the amount of free drug remaining in solution was calculated using absorbance (289 $\mathrm{nm})$ and fluorescence (excitation $480 \mathrm{~nm}$, emission $590 \mathrm{~nm}$ ) measurements, respectively. Subtracting the residual amount left in the supernatant from the initial starting amount allowed us to deduce nanoparticle drug loading. The encapsulation efficiency was calculated using equation (1):

(1) Encapsulation efficiency $(\%)=\underline{\mathrm{W} 1} \times 100$ $\mathrm{W} 2$

where W1 is the actual nanoparticle drug loading and W2 is the theoretical nanoparticle drug loading.

In vitro drug release from silk nanoparticles 
Drug loaded nanoparticles were re-suspended in $0.5 \mathrm{ml}$ of PBS at $\mathrm{pH} \mathrm{4.5,6.0} \mathrm{and} \mathrm{7.4.} \mathrm{The}$ samples were then loaded into a $0.1 \mathrm{ml}$ Slide-A-Lyzer Mini Dialysis Device (MWCO $3500 \mathrm{~g} \mathrm{~mol}^{-}$

${ }^{1}$; Thermo Scientific, Waltham, MA, USA) that was inserted into a $1.5 \mathrm{ml}$ receiving chamber containing $1 \mathrm{ml}$ of buffer at the indicated $\mathrm{pH}$ and then incubated at $37^{\circ} \mathrm{C}$. At the indicated time points, the propranolol or doxorubicin in the receiving chamber was monitored using UV-VISspectroscopy $(289 \mathrm{~nm})$ or fluorescence spectroscopy (excitation $480 \mathrm{~nm}$, emission $590 \mathrm{~nm}$ ), respectively. At each measuring interval, all buffer was replaced with fresh buffer to ensure that sink conditions were maintained throughout the study. Calibration curves of the drugs at the indicated $\mathrm{pH}$ of $4.5,6.0$ or 7.4 were used to quantify drug release. The percentage of cumulative model drug release $(\%)$ was determined as a function of incubation time. Equivalent amounts of freely diffusible propranolol and doxorubicin were used to estimate diffusion-dependent effects of the release setup; at the indicated time points samples were analyzed as detailed above.

\section{In vitro response of macrophages towards silk nanoparticles}

The murine macrophage RAW 264.7 cell line was purchased from ATCC (Manassas, VA, USA). Cells were cultured in DMEM (4.5 g glucose, $110 \mathrm{mg}$ sodium pyruvate, $10 \% \mathrm{v} / \mathrm{v} \mathrm{FBS}$ ), grown in a humidified $5 \% \mathrm{CO}_{2}$ atmosphere at $37^{\circ} \mathrm{C}$ and routinely subcultured every $2-3$ days by scraping cells off the flask and re-plating them at a split ratio of 2 to 10 on tissue culture treated polystyrene (Corning, New York, NY, USA). Macrophage activation was assessed by seeding the cells at a density of $1.4 \times 10^{4}$ cells $/ \mathrm{cm}^{2}$ and allowing them to recover overnight. Next, the culture medium was aspirated and replaced with fresh containing either (i) 5 ng of lipopolysaccharide (LPS, Sigma-Aldrich, St. Louis, MO, USA), (ii) $50 \mu \mathrm{g}$ of native silk nanoparticles, (iii) $50 \mu \mathrm{g}$ of PEGylated silk nanoparticles and (iv) control medium. Cultures were 
incubated for $24 \mathrm{~h}$ and then the medium was collected and centrifuged at $6,000 \times \mathrm{g}$ for 5 minutes. Assay samples were stored at $-80{ }^{\circ} \mathrm{C}$ and analyzed using mouse tumor necrosis factor alpha (TNF- $\alpha$ ) DuoSet ELISA (R\&D Systems, Minneapolis, MN, USA), according to the manufacturer's instructions.

\section{In vitro cytotoxicity and analysis of freely diffusible drug combinations}

The human breast cancer cell lines MCF-7 was purchased from ATCC (Manassas, VA, USA). Cells were cultured in DMEM (4.5 g glucose, $110 \mathrm{mg}$ sodium pyruvate, $10 \% \mathrm{v} / \mathrm{v} \mathrm{FBS}, 10 \mu \mathrm{g} / \mathrm{ml}$ insulin), plated on tissue culture treated polystyrene, grown in a humidified $5 \% \mathrm{CO}_{2}$ atmosphere at $37^{\circ} \mathrm{C}$ and routinely subcultured every $2-3$ days. Cells were seeded in 96-well plates at a density of $2 \times 10^{4}$ cells $/ \mathrm{cm}^{2}$ and allowed to recover overnight. Next, propranolol and doxorubicin stock solutions were filter sterilized $(0.22 \mu \mathrm{m}$, PES membrane, Merck Millipore, Billerica, MA, USA) and cells were treated using freely diffusible (i) doxorubicin, (ii) propranolol and (iii) doxorubicin and propranolol combinations (Supplementary Fig. 4). Following a 72 h incubation period during the exponential growth phase, cell viability was determined using 3-(4,5dimethylthiazol-2-yl)-2,5-diphenyltetrazolium bromide (MTT at $5 \mathrm{mg} / \mathrm{ml}$ in PBS); $20 \mu \mathrm{l}$ of MTT was added to each well and cultures were incubated for $5 \mathrm{~h}$. The formazan product was solubilized with $100 \mu 1$ of dimethylsulfoxide and absorbance was measured at $570 \mathrm{~nm}$. Untreated control cells represented $100 \%$ cell viability. For treatment groups the half maximal inhibitory concentration $\left(\mathrm{IC}_{50}\right)$ was calculated.

The impact of freely diffusible doxorubicin and propranolol drug combinations on MCF-7 cells was determined with an isobologram and combination-index methods using CompuSyn 
Software (ComboSyn Inc., Paramus, NJ, USA). First, the $\mathrm{IC}_{50 \text { s }}$ for each drug on its own was determined as detailed above. Next, an isobologram was generated by plotting the propranolol $\mathrm{IC}_{50}$ on the abscissa and doxorubicin $\mathrm{IC}_{50}$ on the ordinate. The straight line fit connecting these $\mathrm{IC}_{50}$ values generated the additive line. Combination data points that fell on the line represented an additive effect, while data points that fell below or above the line represented synergism or antagonism, respectively. The combination index (CI) of doxorubicin and propranolol was calculated with CompuSyn Software (version 1.0), where a $\mathrm{CI}<1$ indicated synergism, $\mathrm{CI}=1$ was additive and $\mathrm{CI}>$ showed antagonism ${ }^{48}$. The most promising drug combination was used for nanoparticle experiments.

\section{In vitro cytotoxicity of drug loaded silk nanoparticles}

Combination therapy delivered via native and PEGylated silk nanoparticles used fixed ratios of $0.01 \mu \mathrm{g}$ doxorubicin and $2.1 \mu \mathrm{g}$ of propranolol for every $0.5 \mathrm{mg}$ of silk nanoparticles. Nanoparticles were prepared as detailed above and loaded with the respective drug (100\% loading efficiency). Next, doxorubicin loaded nanoparticles and propranolol loaded nanoparticles were mixed to obtain the desired doxorubicin and propranolol combination. MCF-7 cells were cultured as detailed above and cells were treated with (i) $0.5 \mathrm{mg}$ native silk nanoparticles, (ii) 0.5 mg PEGylated silk nanoparticles, (iii) $0.5 \mathrm{mg}$ silk nanoparticle containing the fixed drug combination of $0.01 \mu \mathrm{g}$ doxorubicin and $2.1 \mu \mathrm{g}$ propranolol, or (iv) the combination of freely diffusible drugs at the equivalent doses. Following a $72 \mathrm{~h}$ incubation period cell viability was assessed with the MTT as detailed above.

Scanning electron microscopy of MCF-7 cells exposed to drug loaded silk nanoparticles 
MCF-7 cells were seeded on glass coverslips and allowed to recover as detailed above. Cells were exposed to the treatments for $72 \mathrm{~h}$ and then fixed with $2 \% \mathrm{v} / \mathrm{v}$ glutaraldehyde in PBS, washed with $\mathrm{ddH}_{2} \mathrm{O}$ twice, dehydrated and critical point dried (EM CPD300, Leica Microsystems, Wetzlar, Germany) as detailed elsewhere ${ }^{49}$. Samples were then sputter-coated with $15 \mathrm{~nm}$ of gold and analysed by SEM at $5 \mathrm{kV}$ at 300, 700 and 2,000 fold magnification. Counts of MCF-7 neighboring cells were determined manually and plotted using histograms.

\section{Labeling Silk Nanoparticles with Alexa Fluor 488}

A total of $10 \mathrm{mg}$ of native and PEGylated silk nanoparticles were fluorescently labelled. First, silk nanoparticles were resuspended in $0.1 \mathrm{M} \mathrm{NaHCO}_{3}, \mathrm{pH} 8.3$. Next, $1 \mathrm{mg}$ of Alexa Fluor 488 succinimidyl ester (Life Technologies, Carlsbad, CA, USA) was dissolved in anhydrous dimethylsulfoxide (DMSO) at $1 \mathrm{mg} / \mathrm{ml}$ and $100 \mu \mathrm{L}$ of this solution was added to the native and PEGylated silk nanoparticles and allowed to react for $24 \mathrm{~h}$ at room temperature in the dark while stirring. Silk nanoparticles were then centrifuged and the pellets were washed 4 times with acidified water ( $\mathrm{pH}$ 4.6) to remove unbound dye, followed by 3 washes with $\operatorname{ddH}_{2} \mathrm{O}$. The samples were stored at $4{ }^{\circ} \mathrm{C}$ in the dark until use.

\section{Cellular uptake of native and PEGylated silk nanoparticles}

MCF-7 cells were seeded in complete phenol red-free medium at a density of $2 \times 10^{4} / \mathrm{cm}^{2}$ and allowed to recover for $24 \mathrm{~h}$. Next, the cultures were incubated for $5 \mathrm{~h}$ with: (i) $0.3 \mu \mathrm{g} / \mathrm{ml}$ doxorubicin or the equivalent amount of doxorubicin loaded in (ii) $0.5 \mathrm{mg} / \mathrm{ml}$ Alexa Fluor 488 labelled native silk nanoparticles, or (iii) $0.5 \mathrm{mg} / \mathrm{ml}$ Alexa Fluor 488 labelled PEGylated silk 
nanoparticles. Immediately prior to live cell imaging, the culture medium was replaced with fresh complete DMEM medium containing $25 \mathrm{mM}$ HEPES. Cells were imaged for up to 20 minutes using a Leica TCS-SP5 confocal laser scanning microscope (Leica Microsystems GmbH, Wetzlar, Germany) equipped with a 40× magnification water objective with a numerical aperture of 1.25. Alexa Fluor 488 and doxorubicin-associated fluorescence was tracked using a $485 \mathrm{~nm}$ excitation wavelength and acquired sequentially to minimize bleed-through at an emission wavelength of 500-545 $\mathrm{nm}$ and 590-635 nm, respectively. The data were exported to Image J 1.48 (National Institute of Health, USA) for contrast enhancement and were assembled for co-localization.

\section{Statistical analysis}

Data were analyzed using GraphPad Prism 5.0b (GraphPad Software, La Jolla, CA, USA). Sample pairs were analyzed with the Student's t-test. Multiple samples were evaluated by oneway analysis of variance (ANOVA) followed by Bonferroni's multiple comparison post hoc test. An asterisk denotes statistical significance as follows: $* \mathrm{P}<0.05$, $* * \mathrm{P}<0.01$, $* * * \mathrm{P}<0.001$. All data are presented are as mean values \pm standard deviation (SD) and $\mathrm{n}$ reverse to the number of independent experiments.

\section{Results}

\section{Characterisation of PEGylated silk nanoparticles}

Nanoprecipitation generated uniform silk nanoparticles that were of a spherical size (104.20 $\mathrm{nm} \pm 1.7$, polydispersity 0.11 ) and had a net negative charge, resulting in a zeta potential of $56.38 \mathrm{mV} \pm 5.6$ in water (Table 1). The presence of amine, hydroxyl and imidazole groups in the 
silk's primary structure rendered this biopolymer amenable to TsT-activated mPEG conjugation (Fig. 1a). Here, silk nanoparticles were PEGylated using activated PEG and the process was tailored to maximize yields. Pilot studies used a constant weight-based 1:1 ratio of activated PEG to silk nanoparticles, employing $20 \mathrm{mg}$ and $50 \mathrm{mg}$ silk nanoparticle batch sizes. The amount of surface-grafted PEG was significantly higher $(\mathrm{P}<0.05)$ for the $50 \mathrm{mg}$ silk nanoparticle batch $(19.4 \pm 1.93 \%)$ than for the $20 \mathrm{mg}$ batch $(12.1 \pm 2.2 \%)$ (Fig. 1b). Therefore, a $50 \mathrm{mg}$ silk nanoparticle batch size was routinely used for all subsequent studies. In addition to spectrophotometric measurements to quantify PEGylation, the impact of PEGylation on particle size and zeta potential was measured (Table 1). PEGylation significantly increased the apparent size of the silk nanoparticles from $104.2 \mathrm{~nm}$ to $116.4 \mathrm{~nm}$ (Fig. 1c), and significantly decreased the negative surface charge from $-56.38 \mathrm{mV}$ to $-46.71 \mathrm{mV}$ (paired t-test, $\mathrm{P}<0.001$ ) (Table 1).

Table 1 Summary of silk nanoparticle characteristics. Data sets are $\pm S D, n \geq 3$.

\begin{tabular}{lccc}
\hline Sample & Particle size $(\mathbf{n m})$ & PDI & Zeta potential $(\mathbf{m V}) \#$ \\
\hline SNPs & $104.20 \pm 1.70$ & $0.11 \pm 0.01$ & $-56.38 \pm 5.60$ \\
PEG-SNPs & $116.40 \pm 3.23$ & $0.12 \pm 0.02$ & $-46.71 \pm 2.59$ \\
\hline
\end{tabular}

\# Measurements were performed in $\mathrm{ddH}_{2} \mathrm{O}$ 

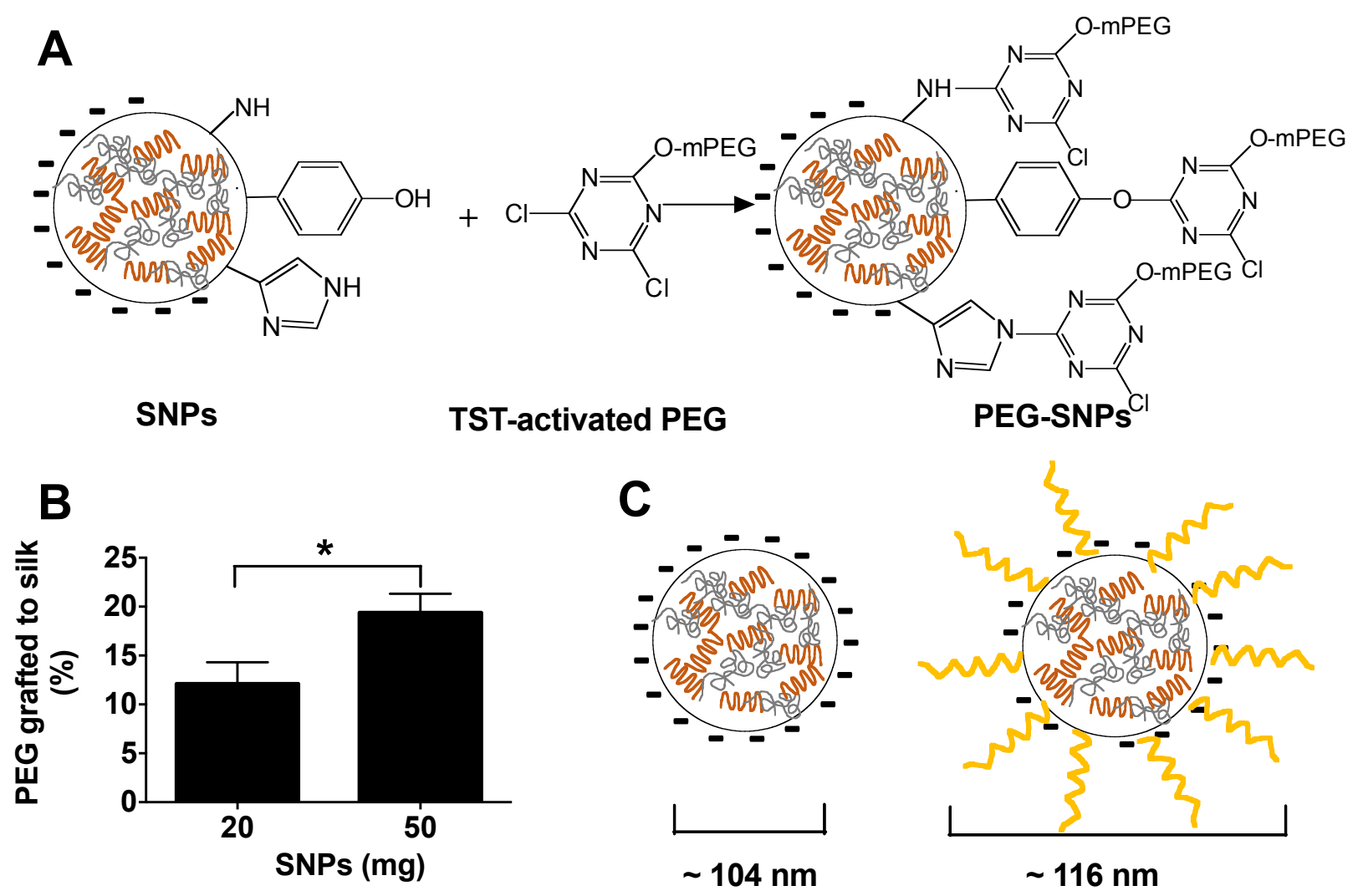

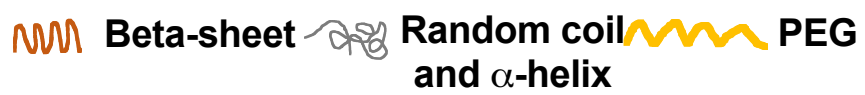

Figure 1. Formation and characterisation of PEGylated silk nanoparticles. (A) The reaction between activated PEG and the silk nanoparticle surface. (B) PEG grafting efficiency to the silk nanoparticle surface for $20 \mathrm{mg} / \mathrm{ml}$ and $50 \mathrm{mg} / \mathrm{ml}$ batches (equivalent to $20 \mathrm{mg}$ and $50 \mathrm{mg}$ of silk, respectively). Paired t-test, ${ }^{*} \mathrm{P}<0.05, \pm \mathrm{S} . \mathrm{D}, \mathrm{n}=3$. (C) A schematic representation of native (left) and PEGylated silk nanoparticles (right). Diagram not drawn to scale.

\section{Surface analysis of native and PEGylated silk nanoparticles}

Zeta potential measurements over a range of $\mathrm{pH}$ were used to study surface charge characteristics of native and PEGylated silk nanoparticles. The zeta potentials of PEGylated silk 
nanoparticles were not substantially different over the $\mathrm{pH} 4.5$ to 8.5 range. In contrast, the surface charges of unmodified silk nanoparticles were sensitive to ion exchange; this was evident as they became more strongly charged at higher $\mathrm{pH}$ values (Fig. 2a). The FTIR spectra of the amide I region of native and PEGylated silk nanoparticles were compared to untreated and autoclaved silk films and PEG (Fig. 2b). The PEGylated silk nanoparticle secondary structure was dominated by $\beta$-sheets. In turn, PEGylated silk nanoparticles had the lowest $\alpha$-helices and turns content of all studied samples. Overall, spectra of native and PEGylated silk nanoparticles showed a high $\beta$-sheet content and substantially lower $\alpha$-helix and random coil structures when compared to untreated, water-soluble silk films (Supplementary Fig. 1).
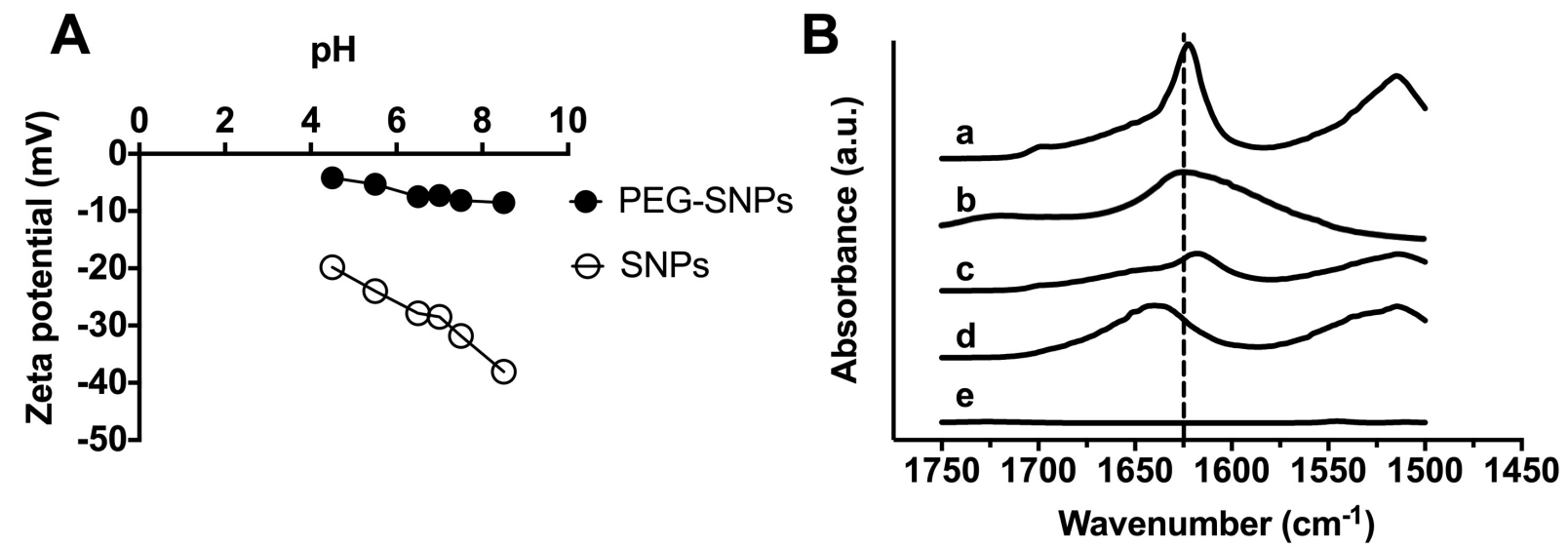

Figure 2. Characteristics of native and PEGylated silk nanoparticles. (A) Zeta potential measurements for silk nanoparticles in $0.01 \mathrm{M}$ PBS at $\mathrm{pH} 4.5$ to 8.5. (B) FTIR absorbance spectra of native and PEGylated silk nanoparticles and reference samples; (a) PEGylated silk nanoparticles; (b) silk nanoparticles; (c) autoclaved silk films; (d) untreated silk films and (e) PEG. Dashed line indicates $\beta$-sheet. 


\section{In vitro stability studies of native and PEGylated silk nanoparticles}

Native and PEGylated silk nanoparticles were prepared and stored for up to 28 days in dd $_{2} \mathrm{O}$ at $25^{\circ} \mathrm{C}$ and subjected to particle size, zeta potential and SEM analysis. During the 28 day storage period, no significant changes were noted in the particle size and zeta potential of the native and PEGylated silk nanoparticles $(\mathrm{P}>0.05)$ (Fig. 3a). Qualitative studies by SEM showed that the native and PEGylated silk nanoparticles were able to maintain their spherical shapes and particle size (100-120 nm) in suspension (Fig. 3b). Exposure of silk nanoparticles to phosphate buffer induced time-dependent aggregation of native silk nanoparticles, resulting in $>400 \mathrm{~nm}$ particle aggregates within 20 minutes (Fig. 3c). In contrast, PEGylated silk nanoparticles showed no signs of aggregation and retained their size throughout the study period (Fig. 3 c,d). 
A

Particle size

Zeta potential

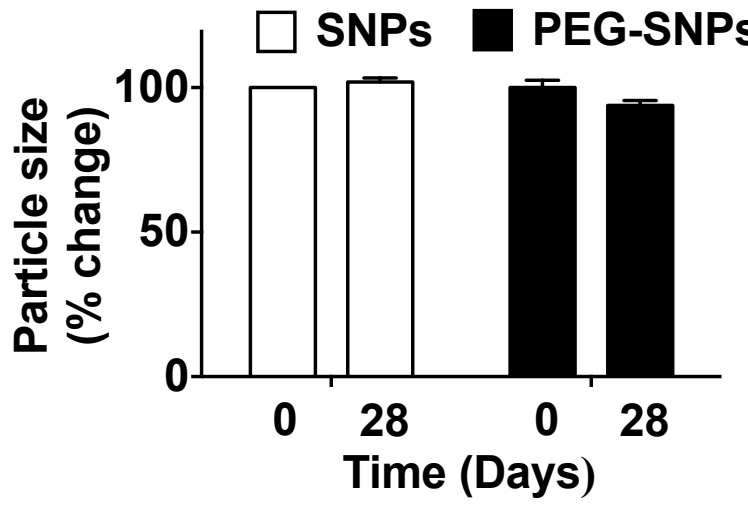

SNPs

B
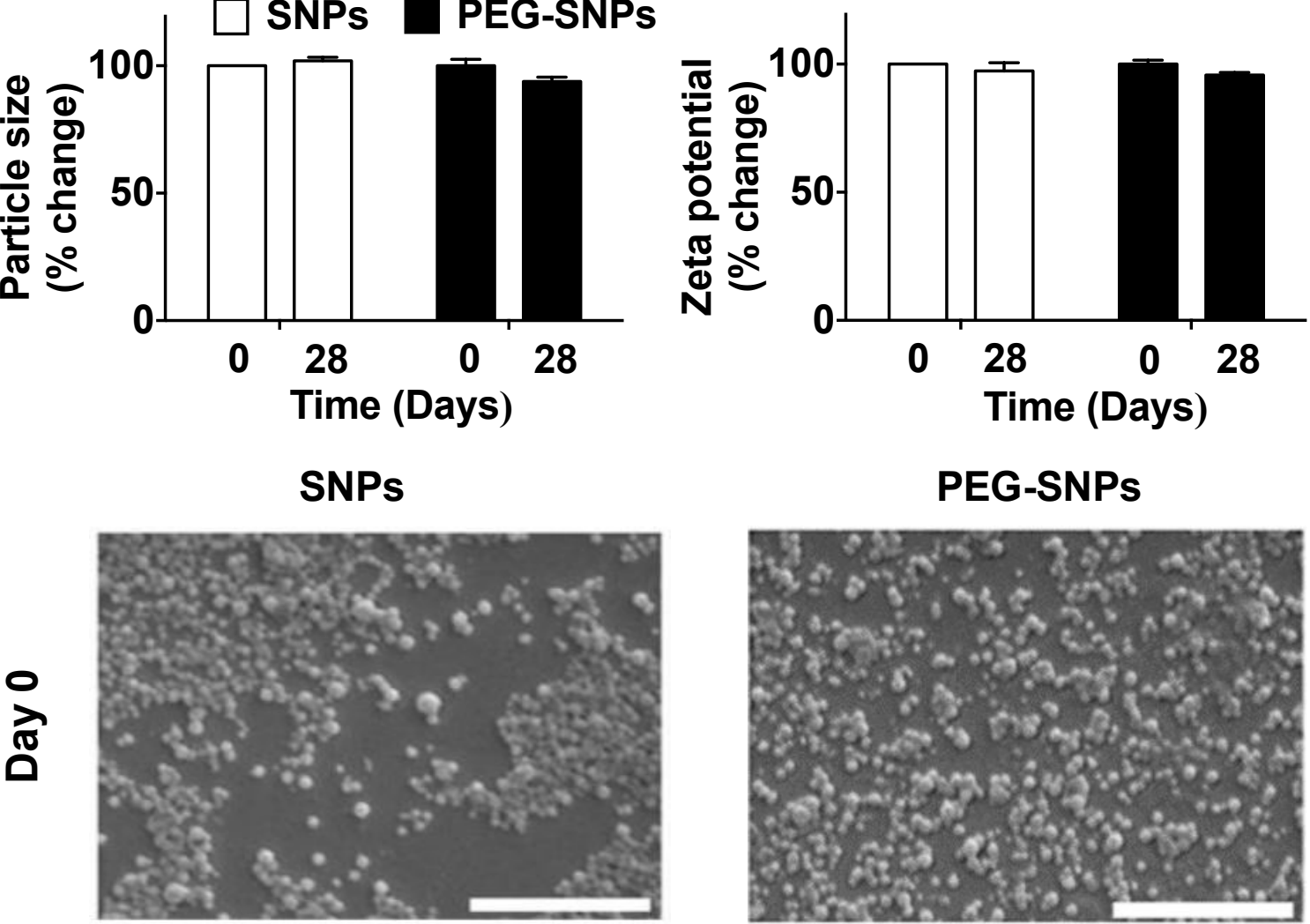

PEG-SNPS
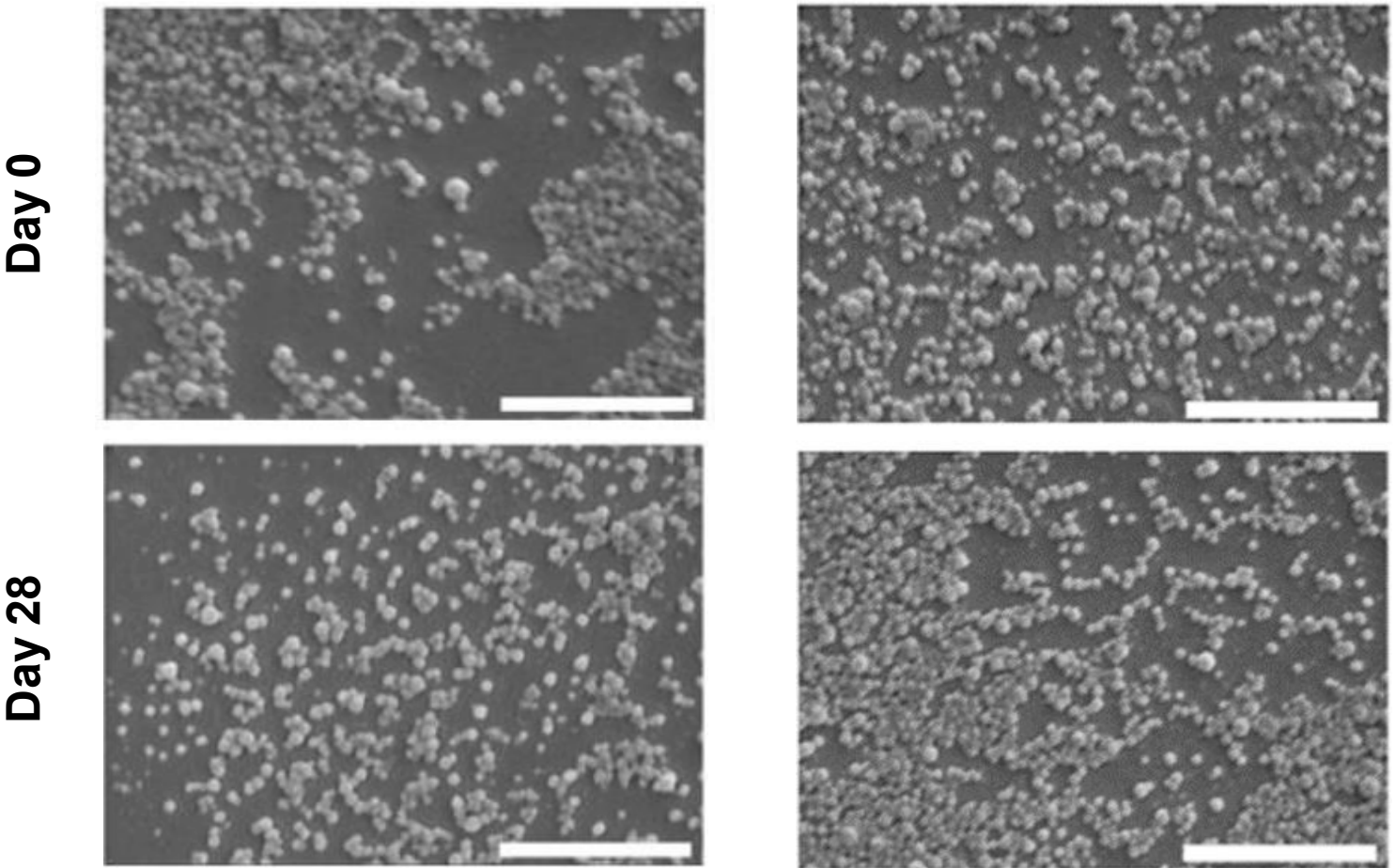

0

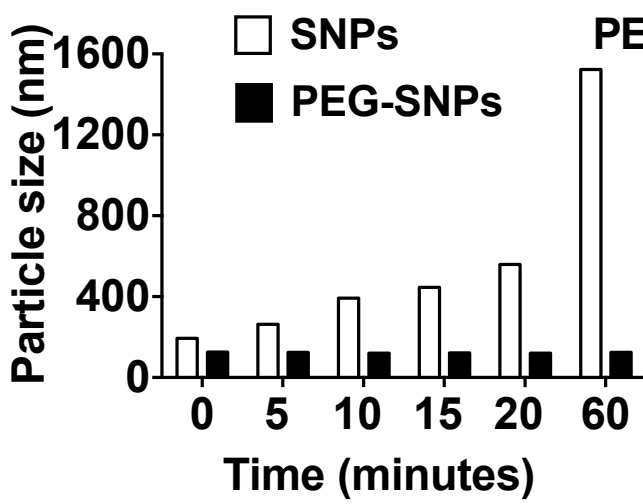

D

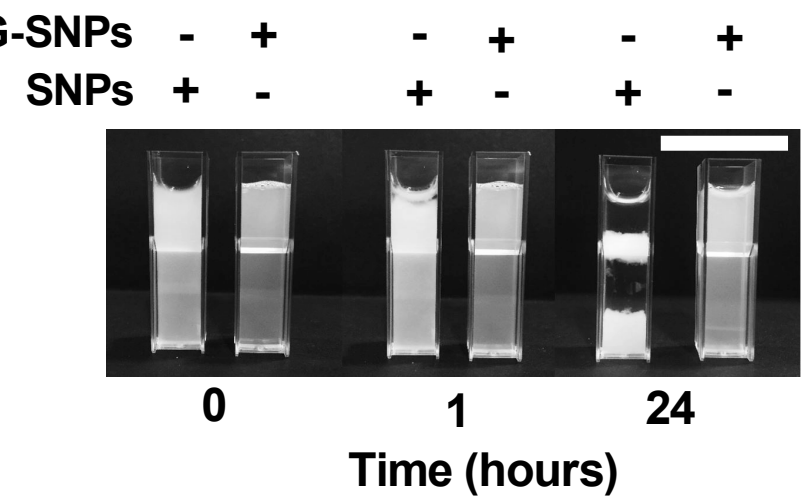


Figure 3. Assessment of native and PEGylated silk nanoparticles. (A) Impact of storage temperature and time on native and PEGylated silk nanoparticle size and zeta potential $( \pm \mathrm{SD}$, n=3). (B) SEM images of native and PEGylated silk nanoparticles stored at $25^{\circ} \mathrm{C}$ for 4 weeks (scale bar $1 \mu \mathrm{m})(\mathbf{C})$ Particle size of SNPs and PEG-SNPs exposed to $0.1 \mathrm{M}$ phosphate buffer at 0 to 60 minutes post exposure and their (D) qualitative assessment at $0,1 \mathrm{~h}$ and $24 \mathrm{~h}$ (scale bar 2 $\mathrm{cm})$. Samples are presented in micro-cuvettes and representative images are shown. At $24 \mathrm{~h}$ the native silk nanoparticle suspension showed phase separation with nanoparticle aggregation at the top and bottom of the cuvette.

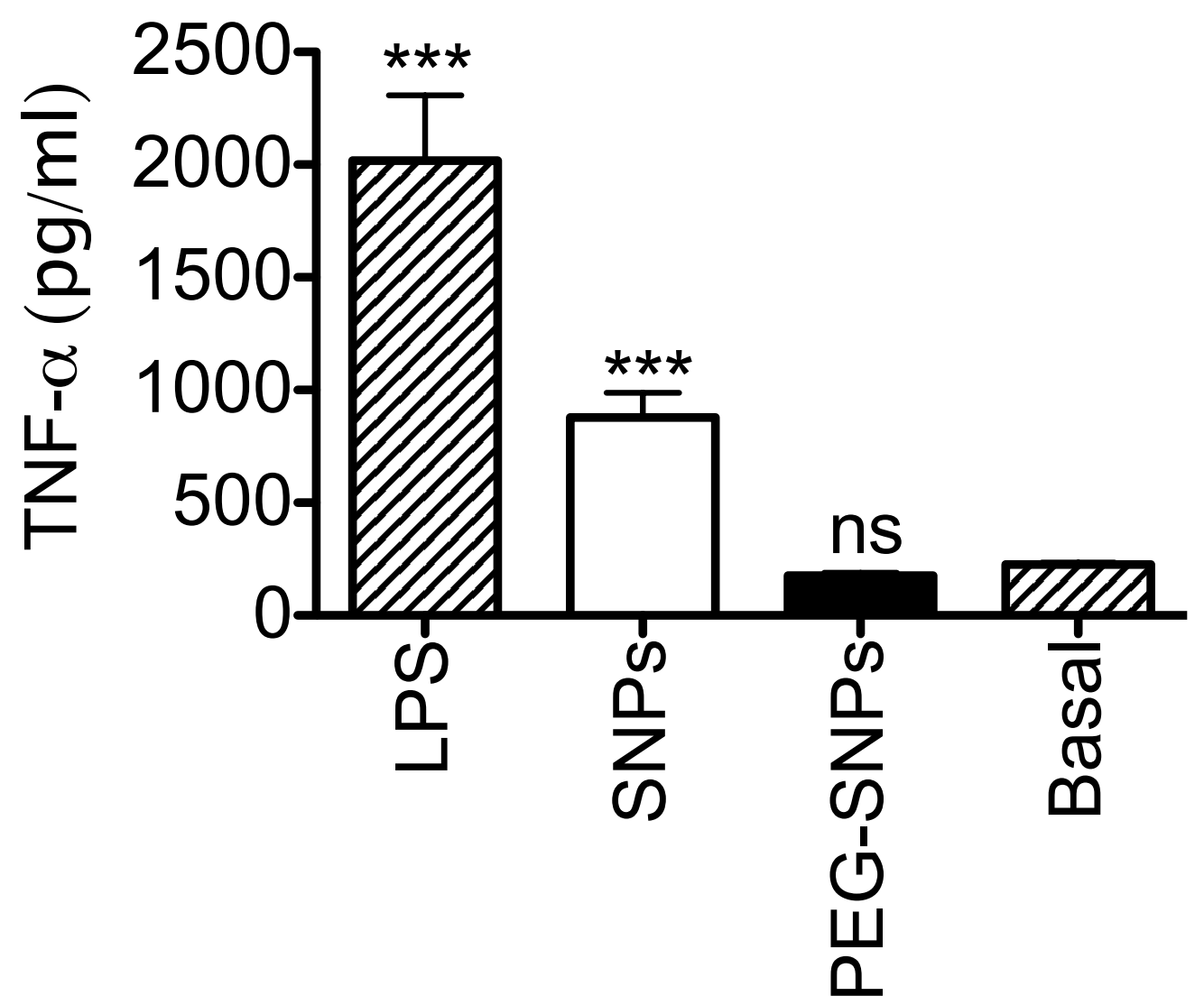


Figure 4. Macrophage response to silk nanoparticles. Quantification of tumor necrosis factor alpha (TNF- $\alpha$ ) in culture supernatants following $24 \mathrm{~h}$ exposure to $5 \mathrm{ng}$ of lipopolysaccharide (LPS, positive control), $50 \mu \mathrm{g}$ of native or PEGylated silk nanoparticles and untreated control cells (basal TNF- $\alpha$ levels). (Significant differences were determined with ANOVA, followed by Bonferroni's multiple comparison post hoc test $* * * \mathrm{P}<0.001, \pm \mathrm{SD}$, error bars are hidden in the plot-symbol when not visible, $\mathrm{n}=3$ ).

\section{PEGylated silk nanoparticles: Modulating macrophage response}

The macrophage response to native and PEGylated silk nanoparticles was determined by quantifying the secreted amounts of TNF- $\alpha$ in the culture medium (Fig. 4). While native silk nanoparticles induced a significant amount of TNF- $\alpha$ release, PEGylated silk nanoparticles showed no differences in secreted TNF- $\alpha$ levels when compared to negative control macrophages. Overall, the highest macrophage response was observed for LPS stimulated cells.

\section{Silk nanoparticles: Drug loading and release}

Pilot studies were conducted using $200 \mathrm{nmol}$ propranolol and 20, 50 and $100 \mathrm{mg}$ silk nanoparticles to determine silk's loading and encapsulation efficiency (Fig. 5a, b). The encapsulation efficiency of $20 \mathrm{mg}$ silk was $46 \%$, which was significantly lower than that of 50 $\mathrm{mg}$ and $100 \mathrm{mg}$ of silk nanoparticles, where $93 \%$ and $98 \%$ of the drug was adsorbed, respectively (Fig. 5b). No statistically significant difference was found between 50 and $100 \mathrm{mg}$ silk nanoparticles, so all subsequent studies were conducted with $50 \mathrm{mg}$. The overall propranolol loading profile for $50 \mathrm{mg}$ of silk nanoparticles indicated a $50 \%$ loading efficiency for 1,420 nmol propranolol (Supplementary Fig. 2). We next determined the loading capacity of 
PEGylated silk nanoparticles. A $50 \mathrm{mg}$ sample of PEGylated silk nanoparticles showed significantly better propranolol loading than $20 \mathrm{mg}$ of PEGylated silk nanoparticles (Fig. 5b). The use of $50 \mathrm{mg}$ of PEGylated silk nanoparticles increased the loading efficiency for propranolol from 93 to $98 \%$ when compared to native silk nanoparticles (Fig. 5b). The use of 50 mg of both native and PEGylated silk nanoparticles resulted in loading of $100 \%$ of $200 \mathrm{nmol}$ doxorubicin (Fig. 5c). We also examined the influence of the adsorbed payload on particle size and zeta potential. The particle size of drug-loaded native and PEGylated silk nanoparticles did not change (data not shown). However, the zeta potential of drug-loaded native or PEGylated silk nanoparticles was significantly different when compared to that of the unloaded nanoparticles (Supplementary Fig. 3). 
A

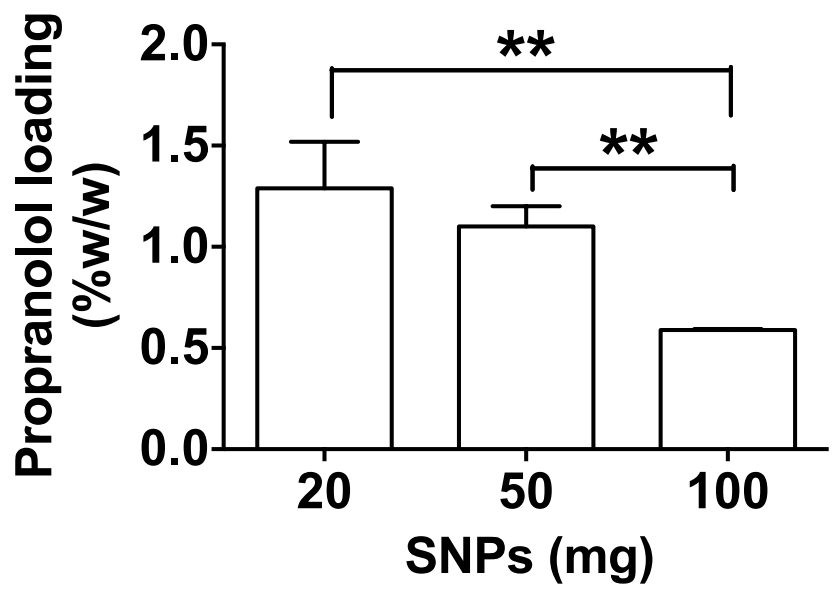

B
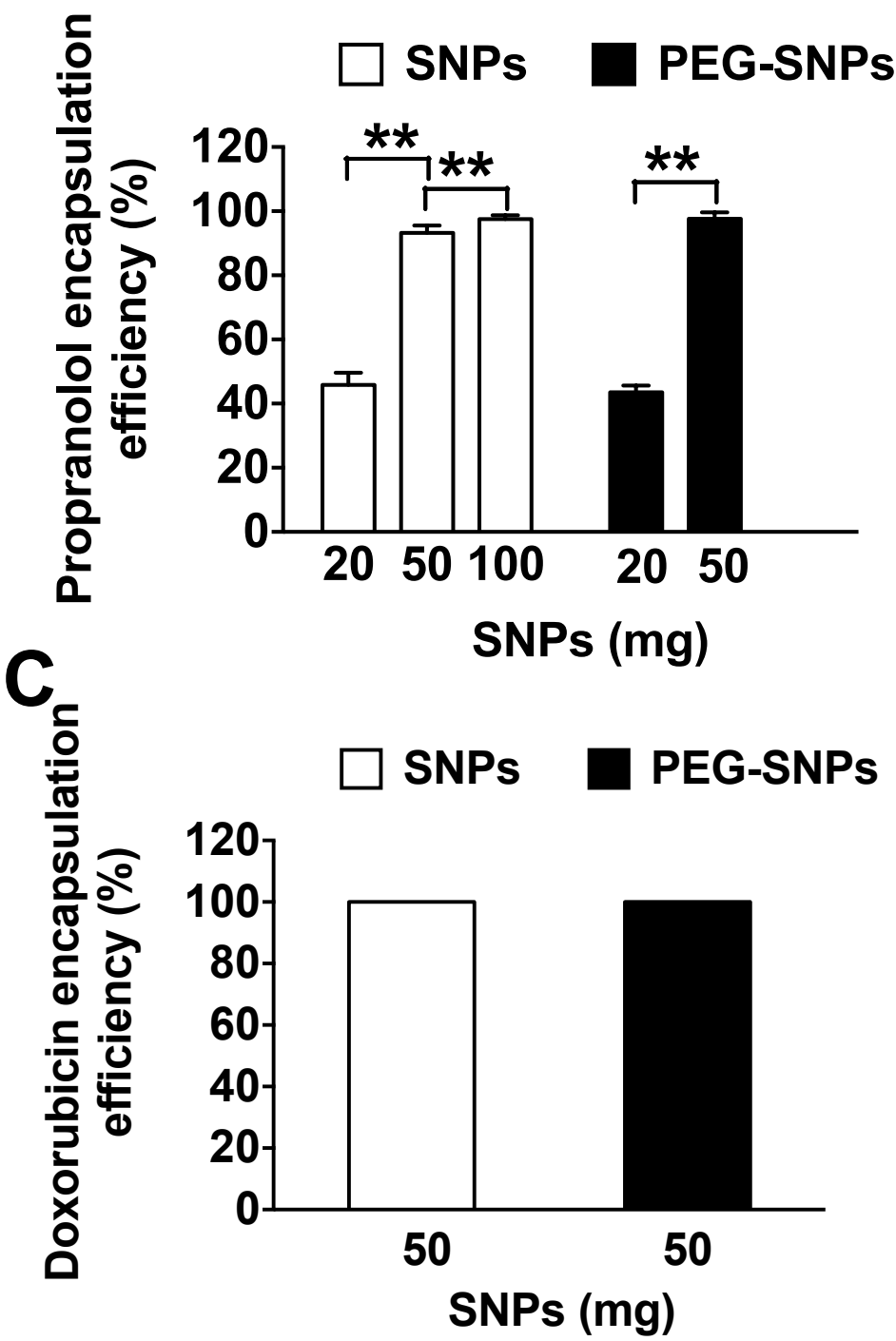
Figure 5. Characterisation of the loading capacity of native and PEGylated silk nanoparticles. (A) Loading efficiency (\%w/w) and (B) encapsulation efficiency (\%) for propranolol in relation to different amounts of silk nanoparticles. (C) Ability of native and PEGylated silk nanoparticles to adsorb doxorubicin. (Significant differences were determined with ANOVA followed by Bonferroni's multiple comparison post hoc test and paired t-test, $* * \mathrm{P}<0.001, \pm \mathrm{SD}$, error bars are hidden in the plot-symbol when not visible, $\mathrm{n}=3$ ).

The release behaviour of drug-loaded nanoparticles was studied over a range of $\mathrm{pH}$ to mimic the $\mathrm{pH}$ of blood plasma $(\mathrm{pH}$ 7.4), early endosomes $(\mathrm{pH}$ 6.0), and lysosomes ( $\mathrm{pH} 4.5)$. For propranolol, almost $90 \%$ of the drug was liberated from native or PEGylated silk nanoparticles after 4 days at $\mathrm{pH} 4.5$ (Fig. 6a, b). Both particles types showed a similar release behaviour for propranolol at $\mathrm{pH} 7.4$ and $\mathrm{pH} 4.5$, while the slowest release of both particle types was found at $\mathrm{pH}$ 6.0. Overall, PEGylation of silk nanoparticles had very little impact on the release behaviour of propranolol at all studied $\mathrm{pH}$ values (Fig. 6a, b). 


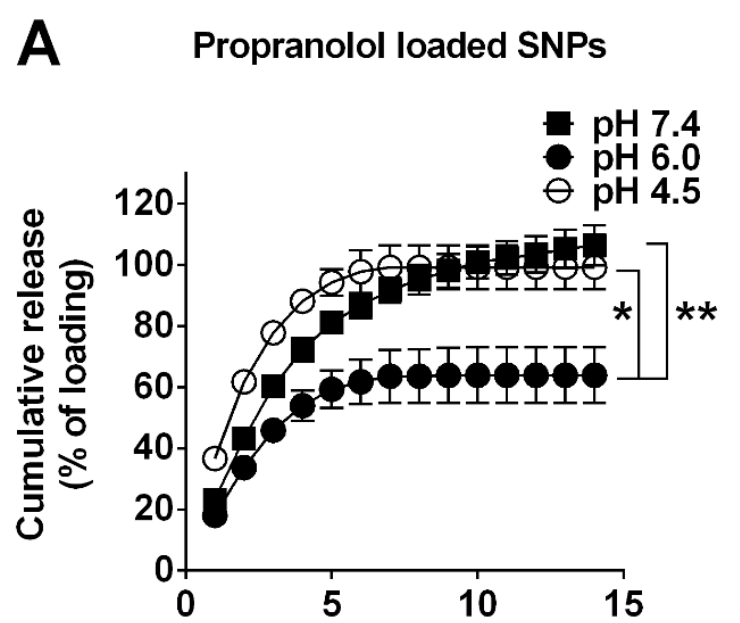

C Doxorubicin loaded SNPs

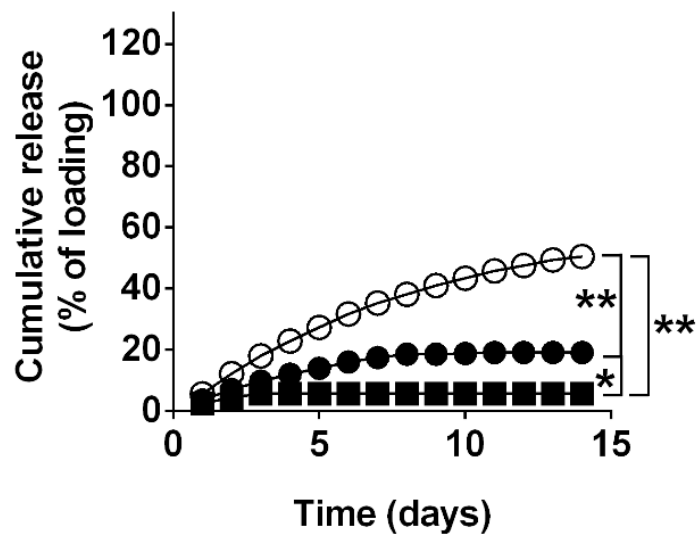

B Propranolol loaded PEG-SNPs

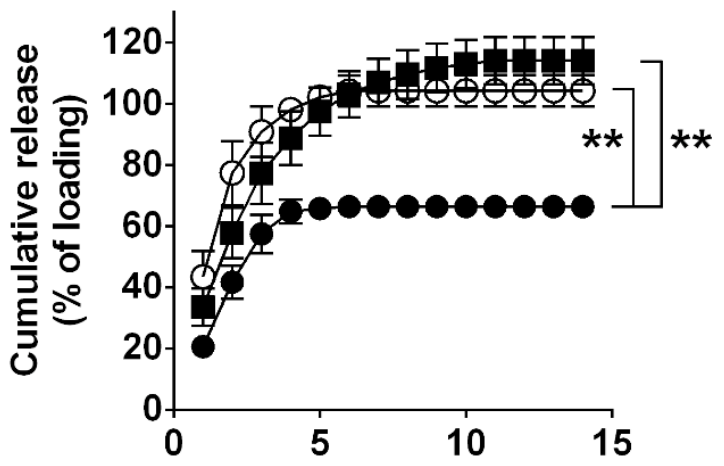

D Doxorubicin loaded PEG-SNPs

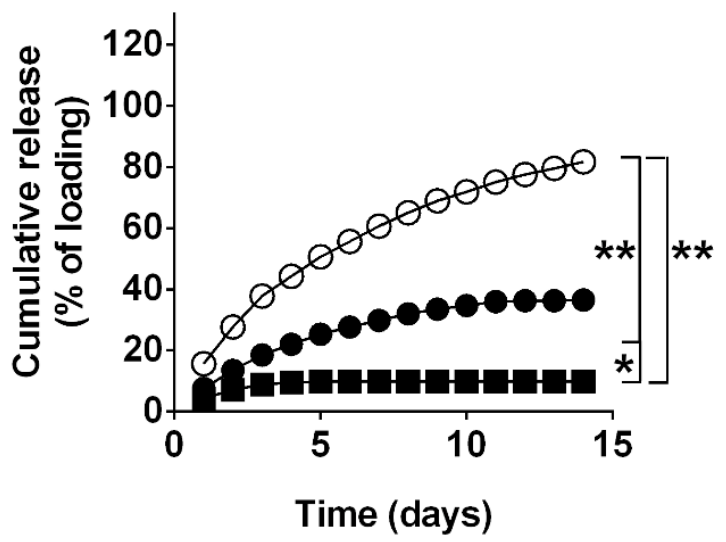

Figure 6. Cumulative drug release from silk nanoparticles. (A) Propranolol loaded silk nanoparticles, (B) propranolol loaded PEGylated silk nanoparticles, (C) doxorubicin loaded silk nanoparticles and (D) doxorubicin loaded PEGylated silk nanoparticles. (One-way ANOVA followed by Bonferroni's multiple comparison post hoc test, ${ }^{*} \mathrm{P}<0.05,{ }^{*} \mathrm{P}<0.001, \pm \mathrm{SD}$; error bars are hidden in the plot-symbol when not visible, $\mathrm{n}=3$ ).

The release of doxorubicin from native or PEGylated silk nanoparticles, on the other hand, showed extended release over 14 days (Fig. 6c, d). The release behaviour of the loaded 
doxorubicin was $\mathrm{pH}$ dependent ( $\mathrm{pH} 4.5>>6.0>7.4)$. About $50 \%$ of the loaded doxorubicin was liberated after 14 days at $\mathrm{pH} 4.5$ from native silk nanoparticles, while $50 \%$ of the drug was released after 5 days at $\mathrm{pH} 4.5$ from PEGylated silk nanoparticles (Fig. 6c, d). Doxorubicinloaded PEGylated silk nanoparticles provided a faster release rate by $24 \mathrm{~h}(16 \%$ versus $6 \%)$ and $72 \mathrm{~h}(38 \%$ versus $18 \%$ at 3 days) and over the course of the study ( $81 \%$ versus $50 \%$ for PEGylated and native silk nanoparticles, respectively) (Fig. 6c, d). Finally, control studies using equivalent doses of freely diffusible doxorubicin and propranolol showed negligible diffusiondependent effects for the employed release set-up (data not shown) and now fluorescence quenching.

\section{Silk nanoparticles for anticancer drug delivery: In vitro cytotoxicity}

The cytotoxicities of native and PEGylated silk nanoparticles were first determined using human breast cancer cells (Fig. 7a, b); both nanoparticle types had an $\mathrm{IC}_{50}>5 \mathrm{mg} / \mathrm{ml}$. Next, silk nanoparticles loaded either with propranolol or doxorubicin were assessed as mono-therapy and as a combination therapy. As controls, analogous experiments with equivalent dose levels and combinations were preformed with unbound, freely diffusible drug. Dose-response curves were established for the freely diffusible drugs and the half maximal inhibitory concentration $\left(\mathrm{IC}_{50}\right)$ was calculated for each drug. These $\mathrm{IC}_{50 \mathrm{~s}}$ were used to assess freely diffusible drug combinations with an isobologram and gave a subsequent CI value of 0.94 for the doxorubicin $(0.1 \mu \mathrm{g} / \mathrm{ml})$ and propranolol (21 $\mu \mathrm{g} / \mathrm{ml})$ drug combination (Supplementary Fig. 4 b). 

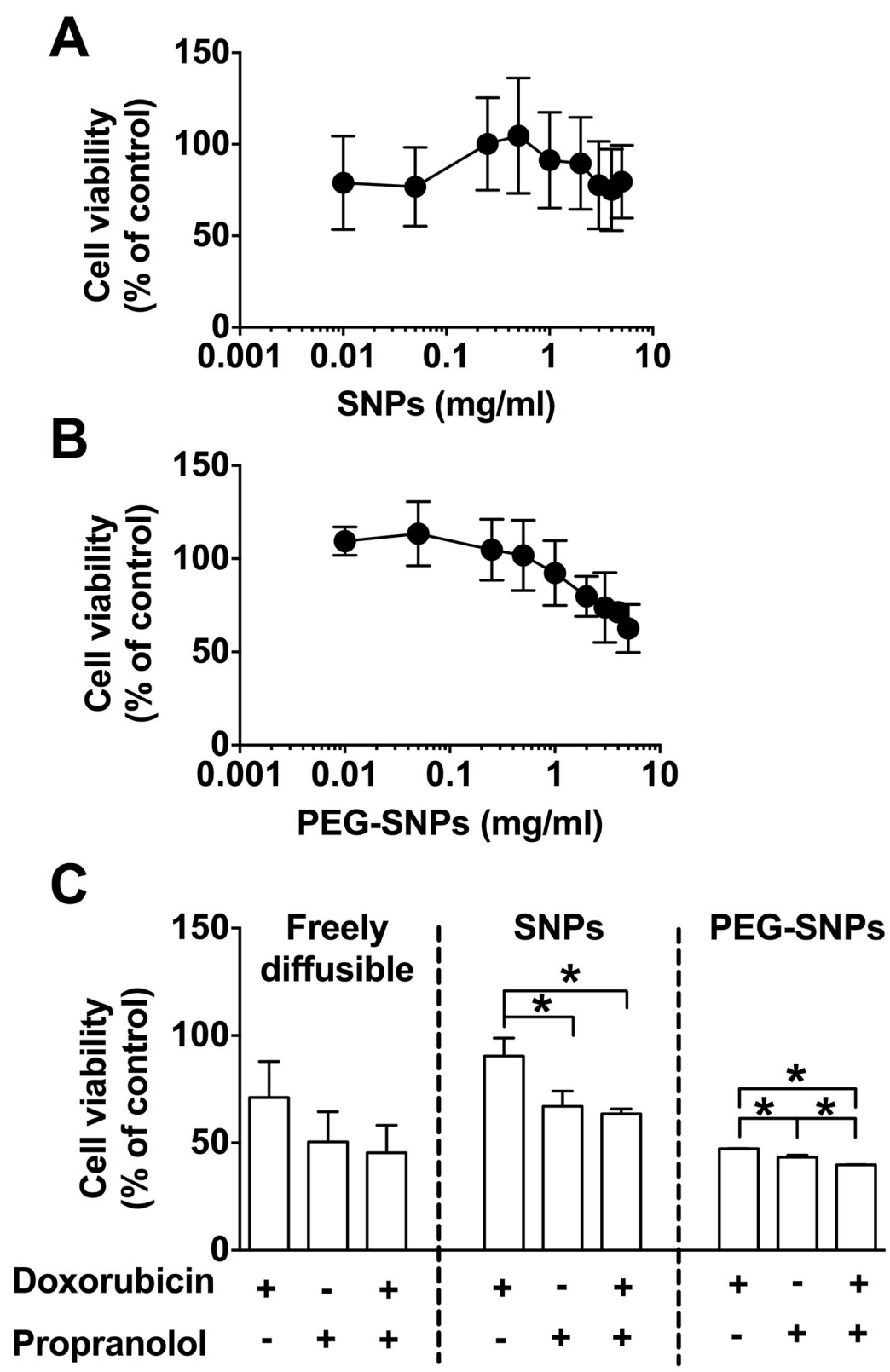

Figure 7. In vitro cytotoxicity of silk nanoparticles against human breast cancer cells. MCF-7 breast cancer cells were exposed for $72 \mathrm{~h}$ to (A) silk nanoparticles, (B) PEGylated silk nanoparticles and $(\mathbf{C})$ doxorubicin $(0.01 \mu \mathrm{g})$ and propranolol $(2.1 \mu \mathrm{g})$ drug combination of freely diffusible and nanoparticle delivered drug combinations. (One-way ANOVA followed by Bonferroni's multiple comparison post hoc test, ${ }^{*} \mathrm{P}<0.05, \pm \mathrm{SD}, \mathrm{n}=3$ ). 
The data sets obtained for freely diffusible drug combinations were then used to inform nanoparticle studies. First, silk nanoparticles were loaded with either propranolol or doxorubicin, next drug loaded silk nanoparticles were mixed to yield the most promising drug combination (i.e. $0.01 \mu \mathrm{g}$ doxorubicin and $2.1 \mu \mathrm{g}$ propranolol) that was then tested in vitro. The combination of propranolol- and doxorubicin-loaded silk nanoparticles significantly reduced cell viability when compared to the equivalent amount of doxorubicin (Fig. 7c). The greatest reduction in cell viability was observed for drug loaded PEGylated silk nanoparticles; they outperformed the freely diffusible treatment groups and showed a significant greater cytotoxicity than drug loaded native silk nanoparticles (Fig. 7c). These cytotoxicity measurements were underpinned by SEM analysis of MCF-7 (Fig. 8). Cells exposed to doxorubicin- and propranolol-loaded native and PEGylated silk nanoparticles showed substantial morphological changes when compared to control cells (Fig. 8 a-h). Control MCF-7 cells had a large number of plasma membrane microvilli (Fig. 8e and i) that were not found in drug-treated cells; overall, the drug-treated cells had a smoother appearance (Fig. $8 \mathrm{f}-\mathrm{h}$ ), with evidence of plasma membrane-associated native and PEGylated silk nanoparticles (Fig. 8 g, h). SEM images were quantitatively analyzed by determining the number of cell neighbors (Fig. 8 j). Cells treated with either freely diffusible drug or the silk nanoparticle-drug combination showed a similar reduction in neighboring cells when compared to untreated cells (Fig. 8j). 

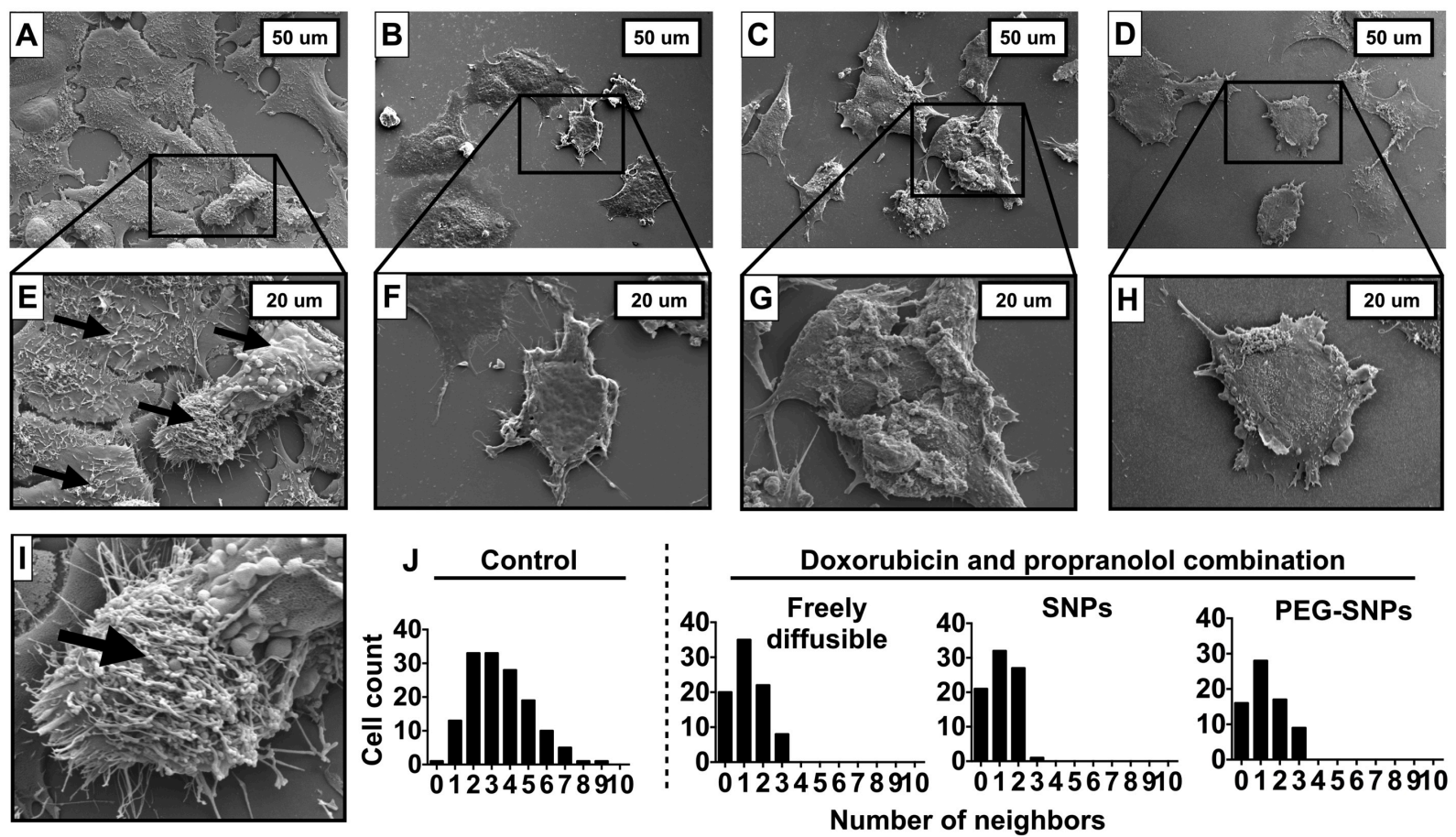

Figure 8. Scanning electron microscopy of human breast cancer cells exposed to drug combinations. (A, E, I) MCF-7 control cells displaying typical cluster-like arrangements with plasma membrane microvilli (arrows $\mathbf{E}$ and $\mathbf{I}$ ). Cells treated with the drug combination of $(\mathbf{B}, \mathbf{F})$ freely diffusible propranolol $(2.1 \mu \mathrm{g})$ and doxorubicin $(0.01 \mu \mathrm{g})$ and the drug combination at the equivalent amounts delivered using $(\mathbf{C}, \mathbf{G})$ native and $(\mathbf{D}, \mathbf{H})$ PEGylated silk nanoparticles. (J) Qualitative analysis of cell neighbors; MCF-7 control cells, cells treated with the freely diffusible drug combination and the drug combination at the equivalent doses delivered using silk nanoparticles.

\section{Cellular uptake of native and PEGylated silk nanoparticles}

The intracellular distribution of doxorubicin-loaded native and PEGylated silk nanoparticles was visualized by confocal live cell imaging. Native silk nanoparticles had a propensity to form 
aggregates in the culture medium, resulting in substantial amounts of doxorubicin-loaded silk nanoparticles attaching to the cell plasma membrane (Fig. 9a). Nonetheless, cytoplasmic doxorubicin and both doxorubicin- and nanoparticle-associated fluorescence were evident in endocytic vesicles (Fig 9a-d). In contrast, doxorubicin-loaded PEGylated silk nanoparticles showed no aggregation and extensive perinuclear accumulation was evident in endocytic vesicles following a $5 \mathrm{~h}$ incubation. Furthermore, tracking of the doxorubicin-associated fluorescence showed substantial doxorubicin-associated fluorescence in the nucleus (Fig. 9g), but no nanoparticle-associated fluorescence (Fig. 9 f). 

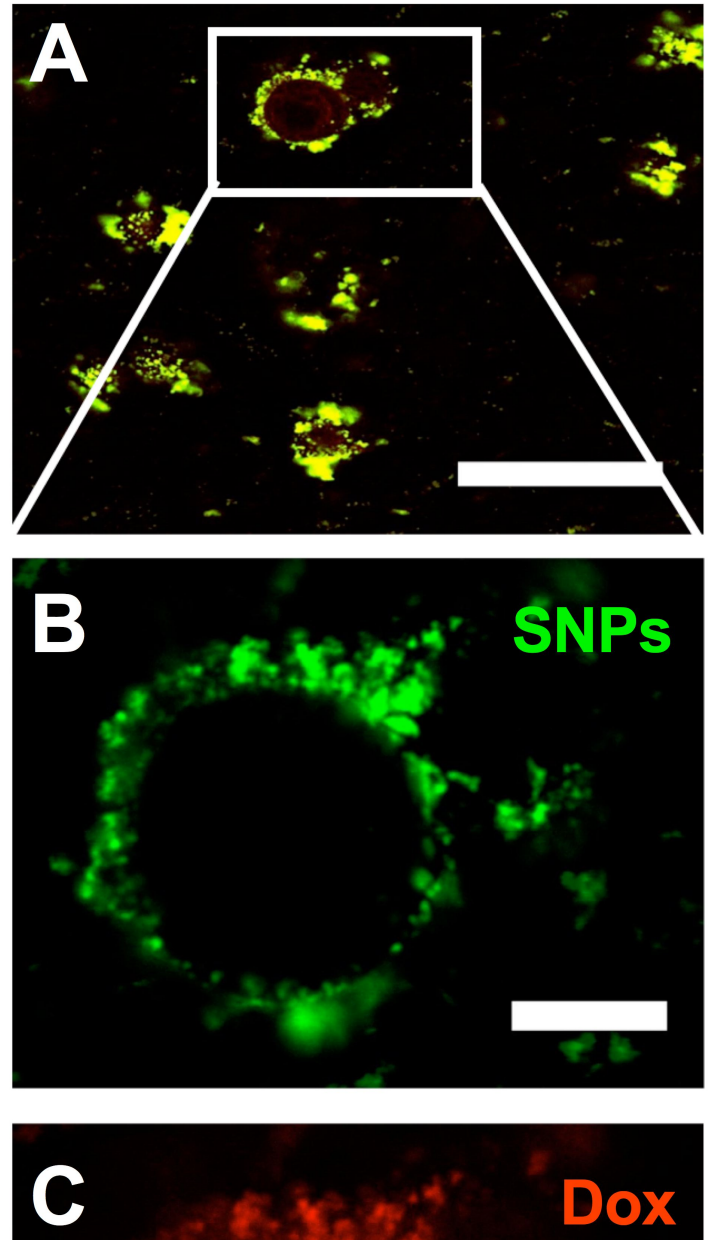

D 'Mếrged

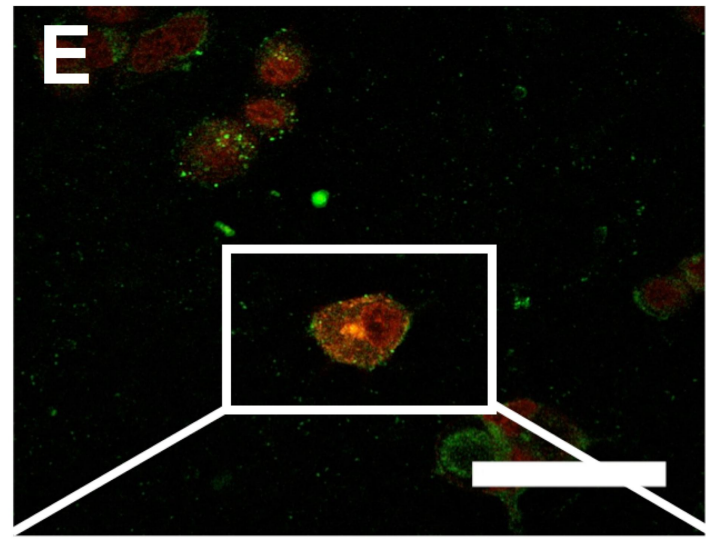

두

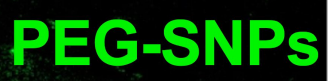

$\star$

G

Dox

$\star$

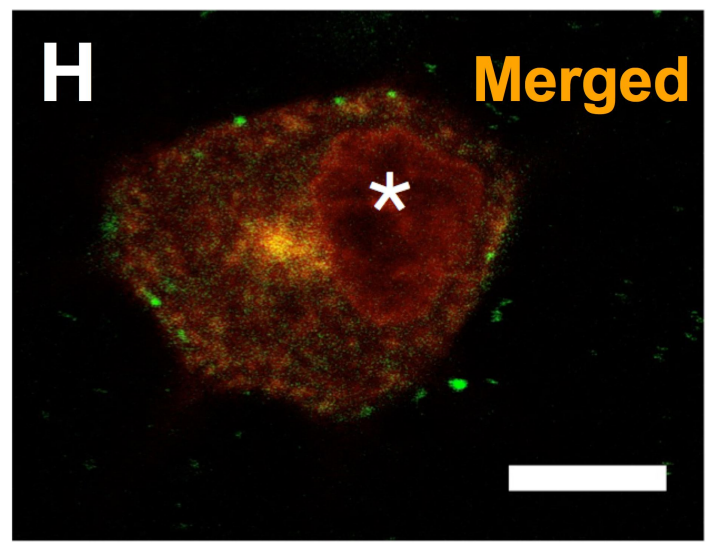


Figure 9. Live cell confocal fluorescence microscopy of doxorubicin-loaded native and PEGylated silk nanoparticles in MCF-7 cells. Cells were incubated with Alexa Fluor 488 labelled nanoparticles for $5 \mathrm{~h}$ and imaged for doxorubicin-associated and nanoparticle-associated fluorescence. (A - D) Doxorubicin loaded native silk nanoparticles and (E - H) PEGylated silk nanoparticles. Asterisk (*) denotes doxorubicin accumulation in the nucleus. The scale bars for low and high magnification are 10 and $50 \mu \mathrm{m}$, respectively.

\section{Discussion}

Cancer therapy typically uses drug combinations to maximise clinical outcomes. Many anticancer drugs are small molecular weight compounds, where pharmacokinetics, tissue distribution, intracellular drug concentrations and elimination are governed by the physicochemical properties of the drug. Drug administration is typically based on the maximum tolerated dose and drug combinations are often concocted using this principal. However, emerging evidence suggests that cellular drug concentrations are critical for maximising any synergistic effects, because drug combinations can vary from antagonistic to synergistic ${ }^{50}$. For example, a liposomal preparation containing the synergistic 5:1 cyterabinine:daunorubicin molar ratio is in Phase II/III clinical trials (Celator Pharmaceuticals) ${ }^{50}$. The use of this macromolecular drug carrier approach endows the payload with a pre-designed whole body, organ, cellular and subcellular pharmacokinetic profile.

Besides using drugs that have known anticancer indications, an effort is ongoing to repurpose other drugs for use in oncology ${ }^{51}$. Emerging evidence indicates that $\beta$-adrenergic signalling 
regulates multiple cellular processes, including cell proliferation, differentiation and migrationpathways that are implicated in cancer. Epidemiological studies also suggest that $\beta$-blockers favourably affect cancer progression and metastasis in patients ${ }^{52}$. Therefore, this present study set out to determine the ability of silk nanoparticles to deliver both propranolol and doxorubicin in combination. However, the development of a combination nanomedicine that would also be applicable in in vivo applications first required refinement of the carrier to minimise MPS accumulation.

PEGylation is one of the most popular ways to modify biomaterial surfaces. PEG is frequently used to modify macromolecular drug carriers such as nanoparticles and liposomes, as well as proteins, antibodies and aptamers ${ }^{17,}{ }^{18}$. The overall result of PEGylation is an improved pharmacokinetic profile when compared to the unmodified parent molecule. PEGylated macromolecules have been used clinically for more than 20 years with a remarkable safety track record ${ }^{53}$. PEG is non-biodegradable and predominately eliminated via urinary clearance; therefore, the selected molecular weight must be below the renal threshold (typically $<30,000$ $\mathrm{g} / \mathrm{mol}$ ) to ensure adequate elimination ${ }^{53}$.

We used a linear 5,000 g/mol PEG because many clinical products employ this type of PEG molecule ${ }^{53,54}$. Cyanuric chloride-activated PEG (5000 g/mol) has previously been surfacecrafted for macro-scale silk films $\left(18.9 \mathrm{~cm}^{2}\right)$ using a reaction of cyanuric chloride to the amine and hydroxyl groups of silk ${ }^{44}$ at a 1:2.5 silk:PEG ratio; this resulted in a grafting efficiency of $3.5 \%$. These PEG grafted silk films displayed low cell adhesion when compared to the unmodified silk surface ${ }^{44}$. 
In pilot studies we varied both the silk:PEG ratio and the actual concentration of silk nanoparticles used during the conjugation reaction. Here, we selected a 1:1 silk:PEG ratio and a $50 \mathrm{mg}$ silk nanoparticle batch size, which resulted in $19.39 \%$ grafted PEG. Although these conditions are quite different from the work reported for silk films ${ }^{44}$, the final results are not surprising; the nanoscale nature of our particles substantially increases the relative surface area to mass and the overall dynamics of the conjugation reaction. We verified successful PEG grafting by physical measurements of nanoparticle size $(104 \mathrm{~nm}$ and $116 \mathrm{~nm}$ for native and PEGylated silk nanoparticles, respectively) and zeta potential (-56 mV to $-45 \mathrm{mV}$ for native and PEGylated silk nanoparticles in $\mathrm{ddH}_{2} \mathrm{O}$, respectively). These results are in line with the values reported in the literature because PEG is known to increase the apparent particle size and to shield surface charges ${ }^{18}$, leading to a reduced zeta potential. Surface tethered PEG can adopt different configurations. For example, high PEG grafting densities typically leads to a brush like conformation while lower densities result in a mushroom like conformation ${ }^{18}$. These different conformations are reflected in hydrodynamic layer thickness measurements. The radius of gyration $\left(R_{\mathrm{g}}\right)$ for PEG $5,000 \mathrm{~g} / \mathrm{mol}$ is $2.8 \mathrm{~nm}{ }^{55}$ and in the present study the measured hydrodynamic layer thickness was $>2$ fold the $R_{\mathrm{g}}$. This suggested that the most likely conformation of PEG chains extending from the surface of silk nanoparticles adopted a brush conformation ${ }^{55}$. Although PEG reduced the zeta potential, the retention of some negative surface charge is desirable to provide sufficient electrostatic repulsion to prevent nanoparticle aggregation during storage and handling in addition to PEGs' ability to stabilize nanoparticles. Surface grafted PEG typically results in a more neutral zeta potential of nanoparticles (reviewed in ${ }^{18}$ ); for example, PEGylated poly(lactic-co-glycolic acid) copolymer (PLGA) nanoparticles 
showed effective charge reduction across a broad $\mathrm{pH}$ range ${ }^{56}$. In the present study the surface of PEG modified silk nanoparticles was effectively shielded from protonation and de-protonation over the studied $\mathrm{pH}$ range; an observation that was not made with native silk nanoparticles (Fig 2a). Because the zeta potential is dependent on the solvent system used, the measured zeta potentials are different for those reported in Table 1 and Fig. 2 a.

We also confirmed the silk nanoparticle stability in water over 28 days, using both qualitative and quantitative measurements. The observation of stability of silk nanoparticles in water is encouraging because any drug carrier developed with a pharmaceutical application in mind needs to be sufficiently stable during storage (e.g. shelf life) and handling if it is to be a viable contender for subsequent clinical development.

However, silk nanoparticles intended for parental administration come into contact with physiological fluids, not pure water. We therefore mimicked this contact by exposing silk nanoparticles to PBS and measuring the particle size (Fig. 3). The direct comparison of native and PEGylated silk nanoparticles clearly showed that surface grafted PEG was critical for stabilizing silk nanoparticles in PBS (Fig. 3c, d). Simple inclusion of PEG in the native silk particle solution (i.e., no covalent attachment to the surface) was not sufficient to achieve equivalent particle stability (data not shown).

PEGylation to synthetic nanoparticles is typically supported by FTIR and/or nuclear magnetic resonance (NMR) analysis ${ }^{18}$. Successful verification of this type of covalent linkage for the biopolymer silk is a recognized challenge ${ }^{57}$; this also includes the reaction of cyanuric chloride- 
activated PEG with silk ${ }^{44}$. We acknowledge that the lack of these measurements is a limitation of the current study, although the evidence presented (Table 1, Supplementary Fig. 1 and Fig. 1 to 4) strongly suggests the successful covalent grafting of PEG onto silk nanoparticles.

Next, we examined the macrophage response towards silk nanoparticles. Previous studies have clearly demonstrated that $\mathrm{TNF}-\alpha$ release from macrophages in response to nanoparticles is a valuable marker for assessing the status of the MPS ${ }^{58-60}$. The amount of TNF- $\alpha$ measured for the positive control was several fold higher than the levels determined for native silk nanoparticles (Fig. 4), whereas the macrophage response to native silk nanoparticles was comparable to that observed with PLGA nanoparticles (data not shown). More importantly, PEGylation of silk nanoparticles reduced the TNF- $\alpha$ amounts to levels seen with the untreated resting macrophages (Fig. 4). This clearly demonstrated that PEGylation of silk nanoparticles further improved their biocompatibility; the applied "stealth" technology successfully evaded the MPS system using the TNF- $\alpha$ assay.

Next, we examined the ability of PEGylated silk nanoparticles to bind and release drugs. Silk carries a negative charge at $\mathrm{pH} 7.4$ in both native and PEGylated form, as verified here, which facilitates loading of positively charged drugs via electrostatic interactions leading to an overall reduced zeta potential (Supplementary Fig 3). Propranolol (pKa 9.1) and doxorubicin (pKa 8.3) are weakly basic drugs that are protonated at a $\mathrm{pH}$ below their respective pKa values. The Scheibel laboratory demonstrated that the distribution coefficient (log D) and diffusion coefficient $\left(\log \mathrm{D} \mathrm{MW}^{-1}\right)$ are two useful parameters for estimating the loading and encapsulation efficiency of weakly basic, small molecular weight molecules onto recombinant spider silk 
(eADF4(C16)) particles ${ }^{61}$. Log D is a useful indicator for predicting physical properties because it is based on the calculated ratio of unprotonated and protonated states of a molecule in octanol (hydrophobic) and water (hydrophilic), which in turn relates to both $\log \mathrm{P}$ and $\mathrm{pKa}$ of the payload molecule.

Our experiments supported the conclusion that eADF4(C16) particle loading was best for weakly basic payloads with a high $\log \mathrm{D}$ and diffusion coefficient (expressed by the inverse proportionality of molecular weight). However, silk nanoparticles showed a greater encapsulation efficiency for doxorubicin than for propranolol at $\mathrm{pH} 7.4$ despite a lower $\log \mathrm{D}$ 0.35 and $\log \mathrm{D} \mathrm{MW}^{-1} 6 \times 10^{-4}$ values than propanol's $\log \mathrm{D} 1.47$ and $\log \mathrm{D} \mathrm{MW}^{-1} 5 \times 10^{-3}$ values. This discrepancy is likely due to structural differences between B. mori silk and spider silk eADF4(C16). B. mori silk consists of hydrophilic blocks in the heavy chain with negative charges while spider silk eADF4(C16) is very hydrophobic due to its lack of hydrophilic spacers in the silk backbone ${ }^{61}$. Therefore, structural differences in B. mori silk are likely to affect drug loading through a number of mechanisms, including hydrophilic-hydrophilic interactions and $\pi$ $\pi$ stacking of adsorbed doxorubicin resulting in high encapsulation efficiency. The work with eADF4(C16) ${ }^{61}$ and this B. mori silk nanoparticle study used an equivalent amount of propranolol to silk. However, B. mori silk nanoparticles gave a $93 \%$ propranolol encapsulation efficiency while eADF4(C16) particles encapsulated only $45 \%$. This discrepancy could be due to structural differences of the silks; this is also supported by the relatively high negative zeta potential (-56 $\mathrm{mV})$ of $B$. mori silk when compared to the low negative zeta potential $(-22 \mathrm{mV})$ of eADF4(C16) of spider silk. Therefore, B. mori silk nanoparticles are expected to have a better drug loading capacity than eADF4(C16) spider silk systems. Overall, native and PEGylated B. mori silk 
nanoparticles showed excellent drug loading capacity, which is a prerequisite for use as a drug delivery system.

The EPR effect can provide a 50 to 100 -fold accumulation of nanoparticles in the tumour microenvironment when compared to healthy tissues ${ }^{7,10}$. During the nanoparticle journey from the injection site to the tumour microenvironment, nanoparticles encounter various environmental conditions; the blood circulation, the extracellular space of the tumour microenvironment, and the subsequent endocytic uptake and trafficking to endosomes and lysosomes ${ }^{14}$. Therefore, we examined drug release form PEGylated silk nanoparticles across a $\mathrm{pH}$ range that mimicked the conditions encountered in the blood $(\mathrm{pH} 7.4)$, early endosomes $(\mathrm{pH}$ 6.0) and lysosomes ( $\mathrm{pH} 4.5$ ). The release profiles of propranolol and doxorubicin differed despite similar $\log \mathrm{D}$ values across acidic $\mathrm{pH}$ (Fig. 6); $\mathrm{pH}$ dependent release of doxorubicin ( $\mathrm{pH} 4.5>>$ 6.5>7.4) correlated well with previous work ${ }^{33}$. Here, we demonstrated that PEGylated silk nanoparticles retained this characteristic $\mathrm{pH}$-dependent release profile with minimal doxorubicin release at $\mathrm{pH}$ 7.4. However, at acidic $\mathrm{pH}$, doxorubicin release was significantly faster (approx. 2fold) from PEGylated silk nanoparticles than from native ones. Because PEGylated silk showed a reduced zeta potential when compared to native silk $(-56.4 \mathrm{mV}$ versus $-46.7 \mathrm{mV})$, PEG grafting reduced the apparent acidic surface characteristics of silk. However, it is likely that PEGylation also changed the actual surface characteristics of the silk nanoparticles due to the reaction of cyanuric chloride with the silk imidazole, amine, and hydroxyl groups. This, in turn, is likely to reduce the drug-silk charge interactions, which are already less pronounced at a lower $\mathrm{pH}$, cumulating in an even faster doxorubicin release. We speculate that drug release from silk nanoparticles is primarily governed by charge, although we cannot exclude other mechanisms of 
PEG-mediated drug release, such as changes in hydrophilic-hydrophobic balance ${ }^{62}$. In the current study, propranolol also showed a $\mathrm{pH}$-dependent release. Interestingly, cumulative propranolol release at $\mathrm{pH} 6.0$ was significantly lower than at $\mathrm{pH} 4.5$ or 7.4. This is counter intuitive as arguably nearly all propranolol molecules are protonated at this $\mathrm{pH}$. It can be clearly seen that for both PEGylated and non-PEGylated silk nanoparticles nearly $40 \%$ of loaded propranolol remains bound to the silk nanoparticle (Fig. 6a,b) which would imply an interaction between propranolol and silk at this $\mathrm{pH}$. Propranolol has shown to promote $\beta$-sheet formation in amyloids ${ }^{45}$ and may interact with the $\beta$-sheet component of silk nanoparticles at this $\mathrm{pH}$ although further work is required to elucidate propranolol-silk interactions.

We next used human breast cancer cells to examine the ability of drug-loaded silk nanoparticles to deliver drug combinations. Emerging evidence suggests that propranolol has anticancer properties and synergistic effects are observed with chemotherapy. Furthermore, in vitro studies indicated that these effects were dose-dependent and cell-type specific ${ }^{63}$. For example, increasing the concentration of $5 \mathrm{nM}$ paclitaxel to $10 \mathrm{nM}$ could modify the interaction effect from sub-additive to synergistic in MCF-7 human breast cancer cells when combined with 10-50 $\mu \mathrm{M}$ propranolol ${ }^{63}$; $\mathrm{MCF}-7$ cells are luminal $\mathrm{A}$ with an immunoprofile of $\mathrm{ER}^{+}, \mathrm{PR}^{+/}$, HER2 ${ }^{-64}$. However, this synergistic effect of paclitaxel and propranolol was not observed with HBL-100 cells (a putative human 'breast cancer cell line' that has been discontinued) or SK-BR3 (invasive ductal carcinoma, $\mathrm{ER}^{-}, \mathrm{PR}^{-}, \mathrm{HER}^{+}$), where an antagonist dose-response was evident ${ }^{63}$. Based on these data we used MCF-7 cells to examine the biological response of doxorubicin and propranolol drug combinations. Freely diffusible drug combinations showed no synergism but an additive anticancer effect (Supplementary Fig. 4); a similar observation was made for silk 
nanoparticle combinations. The lack of synergism is a limitation of the present study and requires additional optimization to uncover the full potential of silk nanoparticles for combination therapy. Nonetheless, combination therapy significantly reduced cell viability when compared to single drug treatment (Fig. 7) and changed MCF-7 morphology and organization (Fig. 8). Overall, PEGylated silk nanoparticle outperformed native silk nanoparticles for the delivery of single and combination therapy. One possibility for this observation is that PEGylated silk nanoparticles did not aggregate and thereby enabled efficient endocytic uptake and subsequent lysosomal accumulation of the carrier (Fig. 9). PEGylated silk nanoparticle delivering doxorubicin also induced greater cytotoxicity than freely diffusible controls at the equivalent doxorubicin concentration (Fig. 7c). This observation is encouraging but unexpected. Typically nanomedicines designed for intracellular activation do not show their full potential in vitro because cellular uptake is restricted to endocytosis (i.e. an energy dependent process that has a limited cargo uptake capacity) and the lack of EPR-mediated targeting ${ }^{14}$.

We report preliminary uptake studies of silk nanoparticles into MCF-7 breast cancer cells using live cell confocal microscopy. Live cell imaging was preformed to minimize the fixation artefacts typically seen with doxorubicin ${ }^{12}$. Furthermore, we used a $5 \mathrm{~h}$ incubation time to allow the accumulation of silk nanoparticles throughout the entire endocytic pathway. Default trafficking from the plasma membrane into lysosomes typically takes $1 \mathrm{~h}^{13}$, so additional time was allowed to provide sufficient exposure of silk nanoparticles to the low lysosomal $\mathrm{pH}$. Images obtained for PEGylated silk nanoparticles clearly suggested lysosomotropic drug delivery because perinuclear accumulation of drug loaded silk nanoparticles was evident, in addition to exclusive doxorubicin-associated fluorescence in the nucleus (Fig. 9e-h). Overall, PEGylated silk 
nanoparticles showed little plasma membrane binding, in contrast to native silk nanoparticles. PEGylation minimized nanoparticle aggregation in the culture medium (Fig. 3c, d) and thereby modulated endocytic uptake and lysosomal trafficking of discrete silk nanoparticles. These observations are in line with other studies describing the PEGylation of nanoparticles ${ }^{65}$.

\section{Conclusion}

In summary, PEGylated silk nanoparticles were developed, characterized and tested as a potential anticancer drug delivery system. PEGylated silk nanoparticles showed excellent drug loading and release capacity and these nanoparticles were subsequently assessed for their in vitro antitumour efficacy. Here, we demonstrate the first example of silk nanoparticle combination therapy. These findings, when combined with prior in vitro data on silk, support a viable future for silk-based nanomedicines.

\section{Supporting Information Available}

Supplementary Figure 1 Absorbance spectra of silk's amide I region after Fourier selfdeconvolution. Supplementary Figure 2 Encapsulation efficiency of native silk nanoparticles (50 mg) over a range of propranolol amounts. Supplementary Figure 3 Zeta potential of drug loaded native and PEGylated silk nanoparticles. Supplementary Figure 4 In vitro cytotoxicity of freely diffusible doxorubicin, propranolol and drug combinations against MCF-7 breast cancer cells. This material is available at free of charge via the Internet at http://pubs.acs.org

\section{Corresponding Author}


F. Philipp Seib; Tel: +44 141-548-2510; Fax: + 44 141-552-2562; emails:

philip.seib@strathclyde.ac.uk

philipp.seib@SeibLab.com

\section{Author Contributions}

The manuscript was written through contributions of all authors. All authors have given approval to the final version of the manuscript.

\section{Acknowledgements}

The authors would like to thank Petr Formanek for providing electron microscopy advice and technical assistance. Microscopy was performed in the Centre for Biophotonics core imaging facility at the University of Strathclyde. This research was supported by a TENOVUS Scotland Grant S13/8, a Royal Society Research Grant RG2014R2 and Marie Curie FP7 Career Integration Grant 334134 within the 7th European Union Framework Program.

\section{References}

(1) Duncan, R.; Gaspar, R. Mol. Pharm. 2011, 8, 2101-2141

(2) Duncan, R.; Vicent, M.J. Adv. Drug Deliv. Rev. 2013, 65, 60-70

(3) Yin, H.; Kanasty, R.L.; Eltoukhy, A.A.; Vegas, A.J.; Dorkin, J.R.; Anderson, D.G. Nat. Rev. Genet. 2014, 15, 541-555

(4) Sheridan, C. Nat. Biotechnol. 2012, 30, 471-473

(5) Veiseh, O.; Tang, B.C.; Whitehead, K.A.; Anderson, D.G.; Langer, R. Nat. Rev. Drug Discov. 2015, 14, 45-57 
(6) Hrkach, J.; Von Hoff, D.; Mukkaram Ali, M.; Andrianova, E.; Auer, J.; Campbell, T.; De Witt, D.; Figa, M.; Figueiredo, M.; Horhota, A.; Low, S.; McDonnell, K.; Peeke, E.; Retnarajan, B.; Sabnis, A.; Schnipper, E.; Song, J.J.; Song, Y.H.; Summa, J.; Tompsett, D.; Troiano, G.; Van Geen Hoven, T.; Wright, J.; LoRusso, P.; Kantoff, P.W.; Bander, N.H.; Sweeney, C.; Farokhzad, O.C.; Langer, R.; Zale, S. Sci. Transl. Med. 2012, 4, 128ra139

(7) Fang, J.; Nakamura, H.; Maeda, H. Adv. Drug Deliv. Rev. 2011, 63, 136-151

(8) Maeda, H.; Nakamura, H.; Fang, J. Adv. Drug Deliv. Rev. 2013, 65, 71-79

(9) Matsumura, Y.; Maeda, H. Cancer Res. 1986, 46, 6387-6392

(10) Torchilin, V.Adv. Drug Deliv. Rev. 2011, 63, 131-135

(11) Duncan, R. Nat. Rev. Cancer 2006, 6, 688-701

(12) Seib, F.P.; Jones, A.T.; Duncan, R. J. Drug Target. 2006, 14, 375-390

(13) Seib, F.P.; Jones, A.T.; Duncan, R. J. Control. Release 2007, 117, 291-300

(14) Duncan, R.; Richardson, S.C. Mol. Pharm. 2012, 9, 2380-2402

(15) de Duve, C.; de Barsy, T.; Poole, B.; Trouet, A.; Tulkens, P.; Van Hoof, F. Biochem. Pharmacol. 1974, 23, 2495-2531

(16) Owens, D.E., 3rd; Peppas, N.A. Int. J. Pharm. 2006, 307, 93-102

(17) Pasut, G.; Veronese, F.M. J. Control. Release 2012, 161, 461-472

(18) Rabanel, J.M.; Hildgen, P.; Banquy, X. J. Control. Release 2014, 185, 71-87

(19) Veronese, F.M.; Pasut, G. Drug Discov. Today 2005, 10, 1451-1458

(20) Bae, Y.H.; Park, K. J. Control. Release 2011, 153, 198-205

(21) Spiess, K.; Lammel, A.; Scheibel, T. Macromol. Biosci. 2010, 10, 998-1007

(22) Werner, V.; Meinel, L. Eur. J. Pharm. Biopharm. 2015, 
(23) Seib, F.P.; Kaplan, D.L. Istrael J. Chem. 2013, 53, 756-766

(24) Omenetto, F.G.; Kaplan, D.L. Science 2010, 329, 528-531

(25) Wenk, E.; Wandrey, A.J.; Merkle, H.P.; Meinel, L. J. Control. Release 2008, 132, 26-34

(26) Wang, X.; Yucel, T.; Lu, Q.; Hu, X.; Kaplan, D.L. Biomaterials 2010, 31, 1025-1035

(27) Xie, R.-J.; Wu, H.-Y.; Xu, J.-M.; Deng, Q.-M. J Fiber Bioeng Info 2008, 1, 73-80

(28) Gupta, V.; Aseh, A.; Rios, C.N.; Aggarwal, B.B.; Mathur, A.B. Int. J. Nanomedicine 2009, $4,115-122$

(29) Lammel, A.S.; Hu, X.; Park, S.H.; Kaplan, D.L.; Scheibel, T.R. Biomaterials 2010, 31, $4583-4591$

(30) Zhao, Z.; Li, Y.; Chen, A.-Z.; Zheng, Z.-J.; Hu, J.-Y.; Li, J.-S.; LI, G. Ind Eng Chem Res $\mathbf{2 0 1 3}, 52,3752-3761$

(31) Xie, M.-B.; Li, Y.; Zhao, Z.; Chen, A.-Z.; Li, J.-S.; Hu, J.-Y.; LI, G.; Li, Z. J Supercritical Fluids 2015, 103, 1-9

(32) Kundu, J.; Chung, Y.I.; Kim, Y.H.; Tae, G.; Kundu, S.C. Int. J. Pharm. 2010, 388, 242250

(33) Seib, F.P.; Jones, G.T.; Rnjak-Kovacina, J.; Lin, Y.; Kaplan, D.L. Adv. Healthc. Mater. 2013, 2, 1606-1611

(34) Zhang, Y.Q.; Shen, W.D.; Xiang, R.L.; Zhuge, L.J.; Gao, W.J.; Wang, W.B. J. Nanoparticle Res. 2007, 9, 885-900

(35) Zhao, Z.; Li, Y.; Xie, M.B. Int J Mol Sci 2015, 16, 4880-4903

(36) Borkner, C.B.; Elsner, M.B.; Scheibel, T. ACS Appl. Mater. Interfaces 2014, 6, 1561115625

(37) Heim, M.; Keerl, D.; Scheibel, T. Angew. Chem. Int. Ed. Engl. 2009, 48, 3584-3596 
(38) Price, R.; Poursaid, A.; Ghandehari, H. J. Control. Release 2014, 190, 304-313

(39) Xia, X.X.; Wang, M.; Lin, Y.; Xu, Q.; Kaplan, D.L. Biomacromolecules 2014, 15, 908914

(40) Numata, K.; Kaplan, D.L. Adv. Drug Deliv. Rev. 2010, 62, 1497-1508

(41) Pritchard, E.M.; Dennis, P.B.; Omenetto, F.; Naik, R.R.; Kaplan, D.L. Biopolymers 2012, 97, 479-498

(42) Florczak, A.; Mackiewicz, A.; Dams-Kozlowska, H. Biomacromolecules 2014, 15, 29712981

(43) Rockwood, D.N.; Preda, R.C.; Yucel, T.; Wang, X.; Lovett, M.L.; Kaplan, D.L. Nat. Protoc. 2011, 6, 1612-1631

(44) Vepari, C.; Matheson, D.; Drummy, L.; Naik, R.; Kaplan, D.L. J. Biomed. Mater. Res. A 2010, 93, 595-606

(45) Mains, J.; Lamprou, D.A.; McIntosh, L.; Oswald, I.D.; Urquhart, A.J. Chem. Commun. $\mathbf{2 0 1 3}, 49,5082-5084$

(46) Hu, X.; Kaplan, D.; Cebe, P. Macromolecules 2006, 39, 6161-6170

(47) Seib, F.P.; Maitz, M.F.; Hu, X.; Werner, C.; Kaplan, D.L. Biomaterials 2012, 33, 10171023

(48) Chou, T.C. Pharmacol. Rev. 2006, 58, 621-681

(49) Seib, F.P.; Muller, K.; Franke, M.; Grimmer, M.; Bornhauser, M.; Werner, C. Tissue Eng. Part A 2009, 15, 3161-3171

(50) Cortes, J.E.; Goldberg, S.L.; Feldman, E.J.; Rizzeri, D.A.; Hogge, D.E.; Larson, M.; Pigneux, A.; Recher, C.; Schiller, G.; Warzocha, K.; Kantarjian, H.; Louie, A.C.; Kolitz, J.E. Cancer 2015, 121, 234-242 
(51) Pantziarka, P.; Bouche, G.; Meheus, L.; Sukhatme, V.; Sukhatme, V.P. Future Oncol. 2015, 11, 181-184

(52) Ji, Y.; Chen, S.; Xiao, X.; Zheng, S.; Li, K. Onco. Targets Ther. 2012, 5, 391-401

(53) Webster, R.; Didier, E.; Harris, P.; Siegel, N.; Stadler, J.; Tilbury, L.; Smith, D. Drug Metab. Dispos. 2007, 35, 9-16

(54) Greenwald, R.B.; Choe, Y.H.; McGuire, J.; Conover, C.D. Adv. Drug Deliv. Rev. 2003, $55,217-250$

(55) Thierry, B.; Griesser, H.J. J. Mater. Chem. 2012, 22, 8810-8819

(56) Stolnik, S.; Dunn, S.E.; Garnett, M.C.; Davies, M.C.; Coombes, A.G.A.; Taylor, D.C.; Irving, M.P.; Purkiss, S.C.; Tadros, T.F.; Davis, S.S.; Illum, L. Pharmaceutical Research 1994, $11,1800-1808$

(57) Murphy, A.R.; Kaplan, D.L. J Mater Chem 2009, 19, 6443-6450

(58) Bancos, S.; Stevens, D.L.; Tyner, K.M. Int J Nanomedicine 2015, 10, 183-206

(59) Pondman, K.M.; Sobik, M.; Nayak, A.; Tsolaki, A.G.; Jakel, A.; Flahaut, E.; Hampel, S.; Ten Haken, B.; Sim, R.B.; Kishore, U. Nanomedicine 2014, 10, 1287-1299

(60) Thomas, V.; Halloran, B.A.; Ambalavanan, N.; Catledge, S.A.; Vohra, Y.K. Acta Biomater 2012, 8, 1939-1947

(61) Lammel, A.; Schwab, M.; Hofer, M.; Winter, G.; Scheibel, T. Biomaterials 2011, 32, 2233-2240

(62) Fontana, G.; Licciardi, M.; Mansueto, S.; Schillaci, D.; Giammona, G. Biomaterials 2001, 22, 2857-2865

(63) Pasquier, E.; Ciccolini, J.; Carre, M.; Giacometti, S.; Fanciullino, R.; Pouchy, C.; Montero, M.P.; Serdjebi, C.; Kavallaris, M.; Andre, N. Oncotarget 2011, 2, 797-809 
(64) Holliday, D.L.; Speirs, V. Breast Cancer Res. 2011, 13, 215

(65) Wang, T.; Upponi, J.R.; Torchilin, V.P. Int J Pharm 2012, 427, 3-20

Table of Contents Graphic and Synopsis Here.

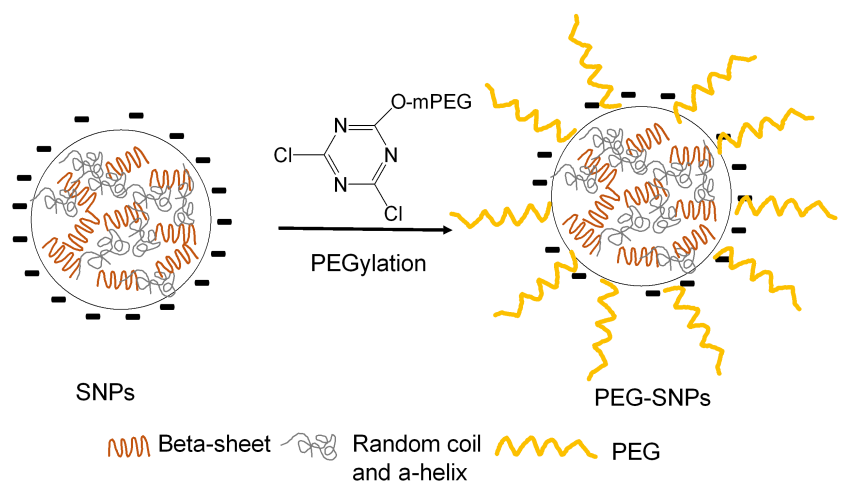



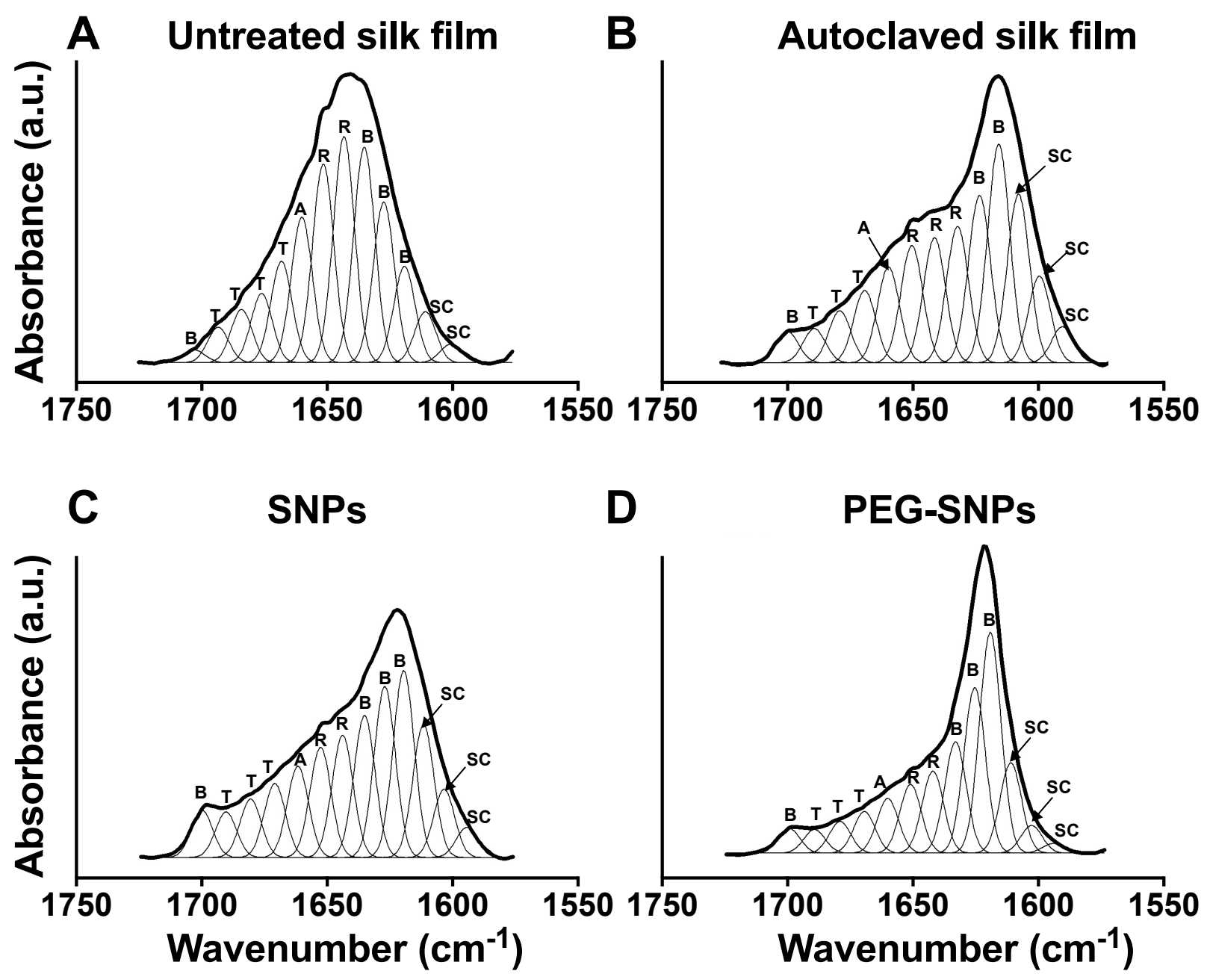

Supplementary Figure 1. Absorbance spectra of silk's amide I region after Fourier selfdeconvolution. Panel (A) untreated silk films, (B) autoclaved silk films, (C) native silk nanoparticles and (D) PEGylated silk nanoparticles. The heavy line represents the deduced absorbance band. The light lines represent the contributions to the amide I band and are marked as (A) $\alpha$-helix, (B) $\beta$-sheet, $(\mathrm{R})$ random coil, (SC) side chain and (T) turn. 


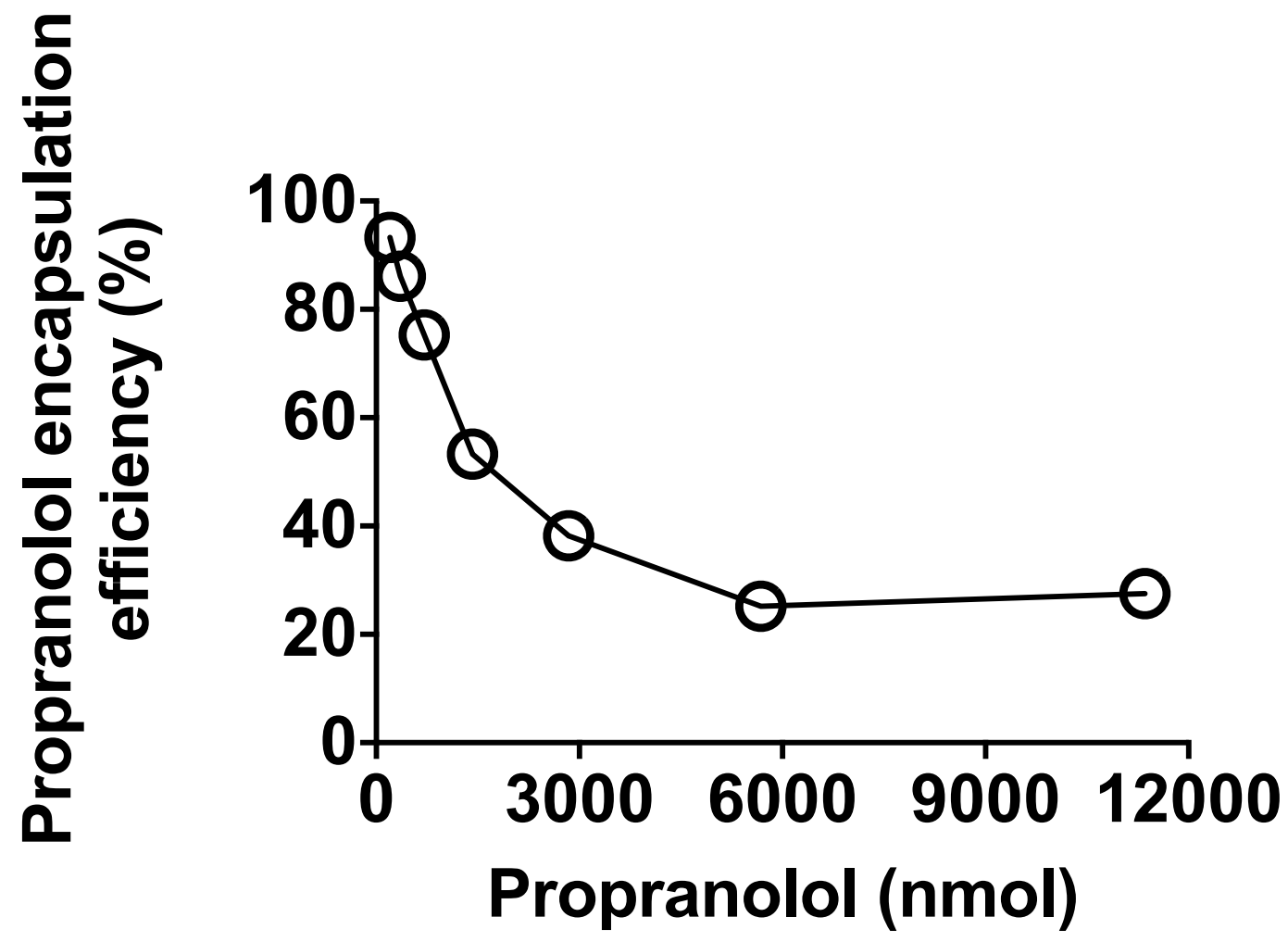

Supplementary Figure 2. Encapsulation efficiency of native silk nanoparticles (50 mg) over a range of propranolol amounts $( \pm \mathrm{SD}$, error bars are hidden in the plot-symbol when not visible). 

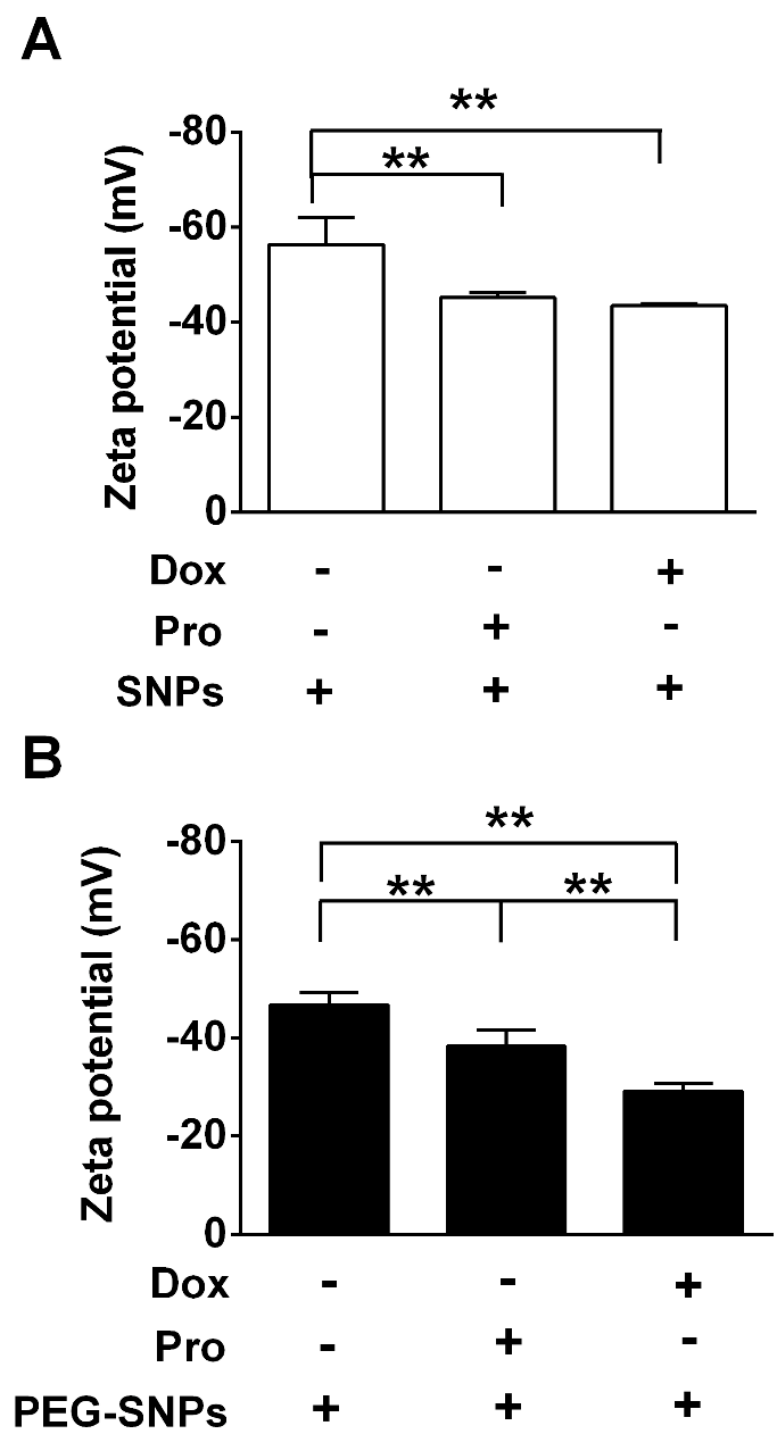

Supplementary Figure 3. Zeta potential of drug loaded native and PEGylated silk nanoparticles.

(A) Native and (B) PEGylated silk nanoparticles were loaded with propranolol $(2.1 \mu \mathrm{g})$ and doxorubicin $(0.01 \mu \mathrm{g})$. (Significant differences were determined with ANOVA followed by Bonferroni's multiple comparison post hoc test, $* * \mathrm{P}<0.001, \pm \mathrm{SD}, \mathrm{n}=3)$. 


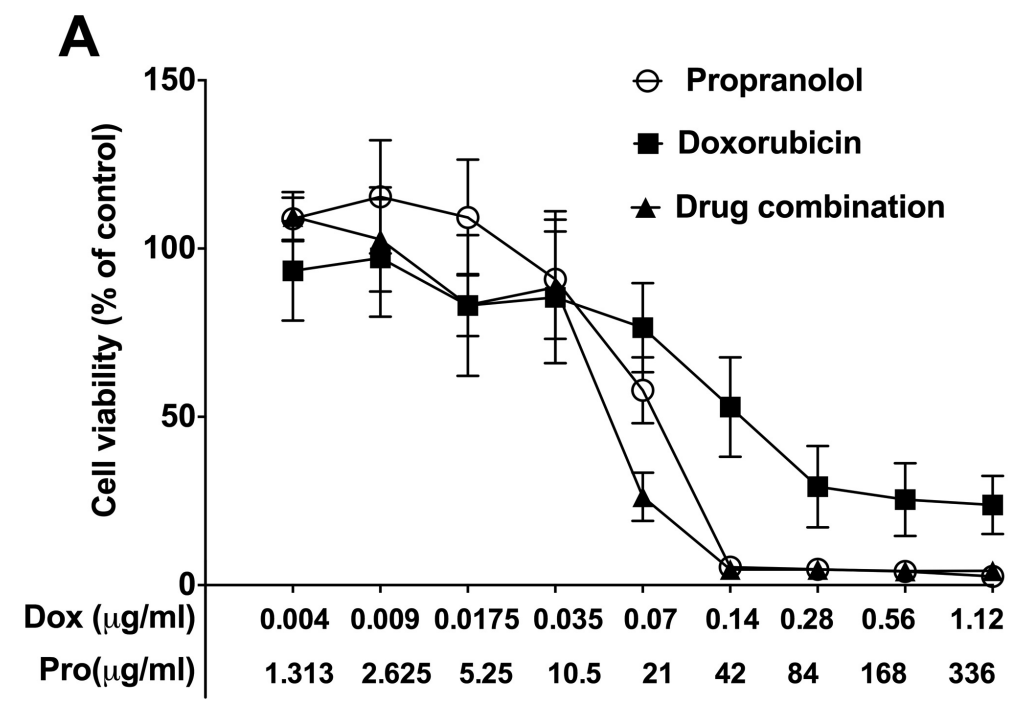

B

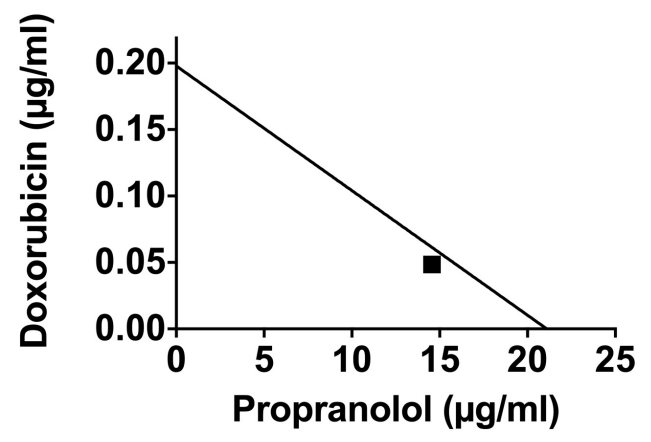

Supplementary Figure 4. In vitro cytotoxicity of freely diffusible doxorubicin, propranolol and drug combinations against MCF-7 breast cancer cells. (A) Growth inhibitory effect of combination of doxorubicin and propranolol in MCF-7 cell lines after $72 \mathrm{~h}$ exposure. (B) Isobologram of doxorubicin and propranolol. Experimental data point represented by square located close to the additive line; for doxorubicin $(0.1 \mu \mathrm{g} / \mathrm{ml})$ and propranolol $(21 \mu \mathrm{g} / \mathrm{ml})$ drug combination. $( \pm \mathrm{SD}$, error bars are hidden in the plot-symbol when not visible $\mathrm{n}=3$ independent experiments). 
